OPEN ACCESS

Edited by:

Gildardo Rivera,

Instituto Politécnico Nacional (IPN),

Mexico City, Mexico

Reviewed by:

Sara M. Robledo,

University of Antioquia, Medellin,

Colombia

Chiara Borsari,

University of Basel, Basel, Switzerland

*Correspondence:

Balamurali M. M

mmbala@gmail.com

Kaushik Chanda

chandakaushik1@gmail.com

Specialty section: This article was submitted to Medicinal and Pharmaceutical Chemistry, a section of the journal Frontiers in Chemistry

Received: 28 October 2020 Accepted: 14 January 2021 Published: 12 March 2021

Citation:

J B, M BM and Chanda K (2021) An Overview on the Therapeutics of Neglected Infectious

Diseases-Leishmaniasis and Chagas Diseases.

Front. Chem. 9:622286. doi: 10.3389/fchem.2021.622286

\section{An Overview on the Therapeutics of Neglected Infectious Diseases-Leishmaniasis and Chagas Diseases}

\author{
Brindha $J^{1}$, Balamurali M. $M^{1 *}$ and Kaushik Chanda ${ }^{2 *}$ \\ ${ }^{1}$ Division of Chemistry, School of Advanced Sciences, Vellore Institute of Technology, Chennai, India, ${ }^{2}$ Department of Chemistry, \\ School of Advanced Sciences, Vellore Institute of Technology, Vellore, India
}

Neglected tropical diseases (NTDs) as termed by WHO include twenty different infectious diseases that are caused by bacteria, viruses, and parasites. Among these NTDs, Chagas disease and leishmaniasis are reported to cause high mortality in humans and are further associated with the limitations of existing drugs like severe toxicity and drug resistance. The above hitches have rendered researchers to focus on developing alternatives and novel therapeutics for the treatment of these diseases. In the past decade, several targetbased drugs have emerged, which focus on specific biochemical pathways of the causative parasites. For leishmaniasis, the targets such as nucleoside analogs, inhibitors targeting nucleoside phosphate kinases of the parasite's purine salvage pathway, 20S proteasome of Leishmania, mitochondria, and the associated proteins are reviewed along with the chemical structures of potential drug candidates. Similarly, in case of therapeutics for Chagas disease, several target-based drug candidates targeting sterol biosynthetic pathway (C14-ademethylase), L-cysteine protease, heme peroxidation, mitochondria, farnesyl pyrophosphate, etc., which are vital and unique to the causative parasite are discussed. Moreover, the use of nano-based formulations towards the therapeutics of the above diseases is also discussed.

Keywords: chagas, leishmaniasis, infectious disease, therapeutics, drugs

\section{INTRODUCTION}

Neglected tropical diseases (NTDs) include a group of diverse infectious diseases that are more prevalent in the tropical and subtropical regions of the world. These diseases are more associated with the poverty zones that have limited health facilities. Moreover, these infections are biologically diverse with 20 different diseases under the list of NTDs including Buruli ulcer, Chagas disease, dengue, chikungunya, dracunculiasis (guinea-worm disease), echinococcosis, foodborne trematodiases, human African trypanosomiasis (sleeping sickness), leishmaniasis, leprosy (Hansen's disease), lymphatic filariasis, mycetoma, chromoblastomycosis and other deep mycoses, onchocerciasis (river blindness), rabies, scabies and other ectoparasites, schistosomiasis, soil-transmitted helminthiases, snakebite envenoming, taeniasis/cysticercosis, trachoma, and yaws (endemic treponematoses). For the past few decades, many pharmaceutical companies have been supportive towards combating these diseases and thereby a significant portion of the economic burden on developing countries was reduced. There are five different strategies adopted by WHO to manage these NTDs: i) preventive chemotherapy, ii) intensified disease management, iii) vector 


\section{Neglected Infectious Diseases}

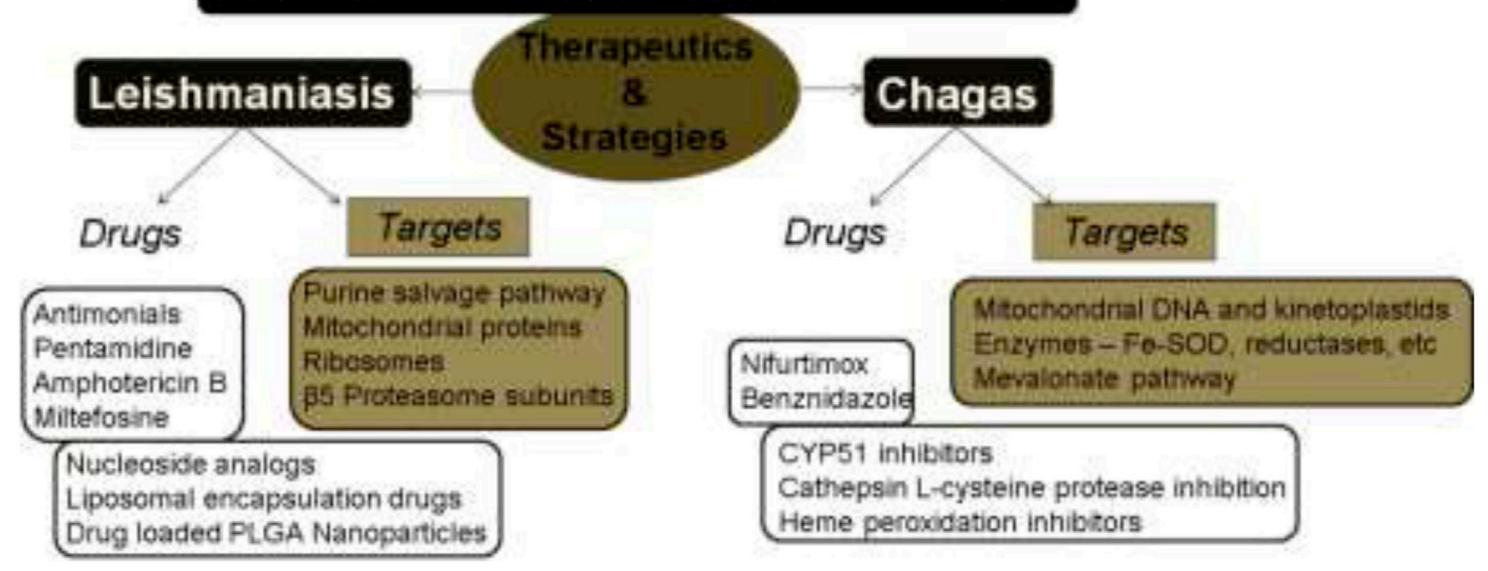

GRAPHICAL ABSTRACT |

control, iv) neglected zoonotic diseases, and v) improved water and sanitation. In the past, several programs to alleviate NTDs were implemented to assist in controlling and eliminating these diseases completely. Many targets proposed in the roadmap of WHO in 2012 have not been achieved to date, though progress is being made to overcome the global impact of NTDs. Recently, the new NTD roadmap for the years 2021-2030 was proposed by WHO (WHO, 2020). WHO has revealed the challenges ahead due to the prevailing COVID-19 pandemic that can hinder the delivery of essential health products for NTDs.

The research on new therapeutic strategies for NTDs focuses on a combination of existing or repurposed drugs, to enhance the efficacy/bioavailability of the available therapeutics; however, the discovery of new drugs also plays a major role in drug discovery for NTDs. Presently available therapies were proved to be toxic and require a longer duration of treatment as compared to the rate of disease progression, along with the development of drug resistance particularly in people infected with NTDs like Chagas disease and leishmaniasis. The above two NTDs are known for the highest mortality rate among others (Hotez et al., 2007).

There are two major ways to identify compounds for these diseases: phenotypic and target-based approaches. The phenotypic approach involves the development of a drug without any knowledge about its target or specific function against the disease (Moffat et al., 2017). In this case, the entire organism, including the pathways/targets, needs to be screened against the drug. The phenotypic approach has been successful in drug discovery and it involves the evaluation of various chemicals against the phenotypes or characteristics observed in an organism (Moffat et al., 2017). But the former lacks understanding of the molecular mechanisms that lead to empirical analysis and delays the progress in obtaining the best drug candidate (Swinney, 2013). The phenotypic approach has the advantage of addressing the problems like cell uptake/efflux and membrane permeability and counterscreening mammalian cells while identifying drug candidates that are active against the whole cell (Borsari et al., 2019). The high-throughput screening mode has enabled the screening of large libraries of drug candidates against whole-cell parasites. In the target-based approach, the first step involves the identification of possible molecular targets that are significantly involved in the disease (Swinney, 2013). This is followed by designing small molecules that interfere with the potential targets in the causative agent (parasite/bacteria/virus) which are absent/different from those present in the infected host system. This approach is rational and exploits information on the genetics, chemistry, and computational sources, for drug discovery. It also quantitatively measures the drug toxicity/ dosages (Capdeville et al., 2002; Durieu et al., 2016). The major drawback in the target-based approach (Lai et al., 2002) is the low productivity caused by poor disease linkages and the molecular complexities that are involved in drug's mode of action (Brown, 2007; Swinney and Anthony, 2011), although in ideal cases, drug discovery can progress through knowledge gained by empirical methods that relate the drug to the molecular mechanisms of action and the involved phenotype to obtain more reliable targets/hypotheses (Garcia-Calvo et al., 2005; Swinney, 2013). There are only a few validated drug targets known against the parasitic diseases and in case of some registered drugs, either the mode of action is poorly understood or it involves various targets (Gilbert, 2013). The correct balance between phenotypic and target-based approaches could possibly lead to successful drug discovery.

Both leishmaniasis and Chagas disease are caused by infectious parasites which are fatal if ignored and untreated. In both cases, the causative parasite shows many unique potential targets in the biochemical machinery. This includes some pathways or targets like the purine/pyrimidine salvage pathways (Bora and Jha, 2020), nucleoside analogs, kinetoplastid proteasomes, mitochondria, etc. There are various potential drug targets available for the treatment of NTDs and intense research is still progressing in this area. The limitations with current therapeutics like toxicity and 
TABLE 1 | Standard drugs against leishmaniasis disease.

\begin{tabular}{|c|c|c|c|c|}
\hline Standard drug & Mechanism of action & Advantages & Disadvantages & References \\
\hline $\begin{array}{l}\text { Pentavalent antimonials, } \\
\text { meglumine antimoniate, } \\
\text { and sodium } \\
\text { stibogluconate (1a) }\end{array}$ & $\begin{array}{l}\text { Not well known, but two model } \\
\text { systems are: Prodrug model- } \\
\text { conversion of } \mathrm{Sb}(\mathrm{V}) \text { to toxic } \mathrm{Sb}(\mathrm{III}) \text { and } \\
\text { intrinsic } \mathrm{Sb}(\mathrm{v}) \text { activity: By complex } \\
\text { formation with ribose/inhibition of } \\
\text { type I DNA topoisomerase }\end{array}$ & Considered as first-line drugs & $\begin{array}{l}\text { - Daily parenteral administration } \\
\text { - Drug resistance } \\
\text { - Side effects include nausea, } \\
\text { vomiting, weakness and myalgia, } \\
\text { abdominal colic, diarrhea, skin } \\
\text { rashes, hepatotoxicity, and } \\
\text { cardiotoxicity }\end{array}$ & $\begin{array}{l}\text { (Berman (1997); dos } \\
\text { Santos Ferreira et al. (2003); } \\
\text { Walker and Saravia (2004); } \\
\text { Zhou et al. (2004) }\end{array}$ \\
\hline $\begin{array}{l}\text { Pentamidine (1c), } \\
\text { pentamidine mesylate, and } \\
\text { pentamidine isethionate }\end{array}$ & $\begin{array}{l}\text { Not known; drug entry through } \\
\text { polyamine/arginine transporters }\end{array}$ & Second line of defense & $\begin{array}{l}\text { Drug resistance which may involve } \\
\text { mitochondria/ABC protein PRP1 }\end{array}$ & $\begin{array}{l}\text { Basselin et al. (1996); } \\
\text { Kandpal and Tekwani } \\
\text { (1997); Mukherjee et al. } \\
\text { (2006); Coelho et al. (2007) }\end{array}$ \\
\hline Amphotericin B (1d) & $\begin{array}{l}\text { Channel/pore formation on interaction } \\
\text { with membrane sterol }\end{array}$ & $\begin{array}{l}\text { - First line of treatment replacing } \\
\text { the antimonials against } \\
\text { visceral leishmaniasis } \\
\text { - Nephrotoxicity overcome by } \\
\text { amphotericin B formulations: } \\
\text { liposomes, nanoparticles, and } \\
\text { emulsions }\end{array}$ & $\begin{array}{l}\text { Toxic with serious side effects: } \\
\text { renal impairment, anemia, fever, } \\
\text { malaise, and hypokalaemia }\end{array}$ & $\begin{array}{l}\text { Hartsel and Bolard (1996); } \\
\text { Neumann et al. (2009); } \\
\text { Cohen (2010); Hamill (2013) }\end{array}$ \\
\hline Miltefosine (1e) & $\begin{array}{l}\text { Apoptosis like cell death, targeting } \\
\text { lipid metabolism, mitochondrial, and } \\
\text { immunomodulatory effects }\end{array}$ & $\begin{array}{l}\text { As monotherapy to treat both } \\
\text { cutaneous and visceral } \\
\text { leishmaniasis }\end{array}$ & $\begin{array}{l}\text { - Side effects, mild-to-moderate } \\
\text { gastrointestinal problems and } \\
\text { mild nephrotoxicity } \\
\text { - Long half-life and teratogenicity } \\
\text { limit the administration of } \\
\text { miltefosine in pregnant women }\end{array}$ & $\begin{array}{l}\text { Jha et al. (1999); Sundar } \\
\text { and Olliaro (2007); Dorlo } \\
\text { et al. (2012a); Dorlo et al. } \\
\text { (2012b) }\end{array}$ \\
\hline
\end{tabular}

resistance have made the discovery of novel drugs against leishmaniasis and Chagas disease more essential.

In this review, we discuss various available drugs, emerging drug targets, and drug candidates identified by target-based approach against the two NTDs, leishmaniasis and Chagas diseases. We have also summarized the various therapeutic strategies that have been adopted in the past and present for the treatment of these two infectious neglected diseases.

\section{LEISHMANIASIS}

Leishmaniasis is one of the infectious NTDs caused by a protozoan parasite vector of genus Leishmania that is transmitted to humans through an infected blood-sucking sandfly. There are about 21 reported species of Leishmania that causes infections in humans and are endemic in the regions of Asia, Africa, America, and also southern parts of Europe. In leishmaniasis, the causative parasite Leishmania species displays a digenetic life cycle, which includes the extracellular motile promastigote, present in the female sandfly vector of the genus Phlebotomus (throughout Africa/Asia) or Lutzomyia (in America) (Matlashewski, 2001), and intracellular nonmotile amastigote that replicates within the phagolysosomes of host human macrophages. For instance, $P$. argentipes and $P$. Salehi were proven to be the sandfly vectors that causes leishmaniasis in India; $P$. celiae, $P$. martini, $P$. saevus, $P$. sergenti, $P$. duboscqi, $P$. longipes, $P$. pedifer, and $P$. sergenti are some of the sandfly vectors of Phlebotomus species that cause leishmaniasis in Ethiopia (Maroli et al., 2013); Lutzomyia longipalpis was the major vector in the north and south Americas to cause leishmaniasis infections (Lainson and
Rangel, 2005). Leishmaniasis infections lead to different kinds of diseases based on the species causing the infection (Pearson and Sousa, 1996; Ghedin et al., 1997). In humans, leishmaniasis is reported in three different forms: visceral, mucocutaneous, and cutaneous (Modabber et al., 2007). Visceral leishmaniasis, also called Kala-Azar caused by Leishmania donovani or L. chagasi, is a serious form of infection, manifested with skin darkening, weight loss, fever, liver/spleen enlargement, and emaciation (Matlashewski, 2001). Visceral leishmaniasis is a chronic infection, associated with high mortality and morbidity. Around $10 \%$ of the cured Kala-Azar patients develop postKala-Azar dermal leishmaniasis, which is chronic with disfigurement of cutaneous nodules (Adams et al., 2013). Dermal leishmaniasis predominantly occurs as localized cutaneous leishmaniasis along with other aggressive forms like diffused cutaneous leishmaniasis, mucosal leishmaniasis, and cutaneous leishmaniasis. They cause several lesions/ disfigurement affecting the psychological well-being of the patients (Alvar et al., 2012). Cutaneous leishmaniasis involves the development of large open sores/lesions from several small lumps at the site of insect bite that eventually heals on its own over an extended period of several months (Matlashewski, 2001; Modabber et al., 2007). Diffused cutaneous leishmaniasis is another form of the disease where lesions are developed over a larger part of the body that resolves only with treatment (Matlashewski, 2001). Mucocutaneous leishmaniasis starts initially as cutaneous leishmaniasis and later spreads to mucous membranes of pharynx, mouth, and nose, depletes the tissues, and causes excessive damage to the face, along with leprosy kind of stigma and impairment of breathing in critical cases (Toledo et al., 2013; Pal et al., 2017; Cruz et al., 2019). Psychiatric disorder is associated with patients with extensive 


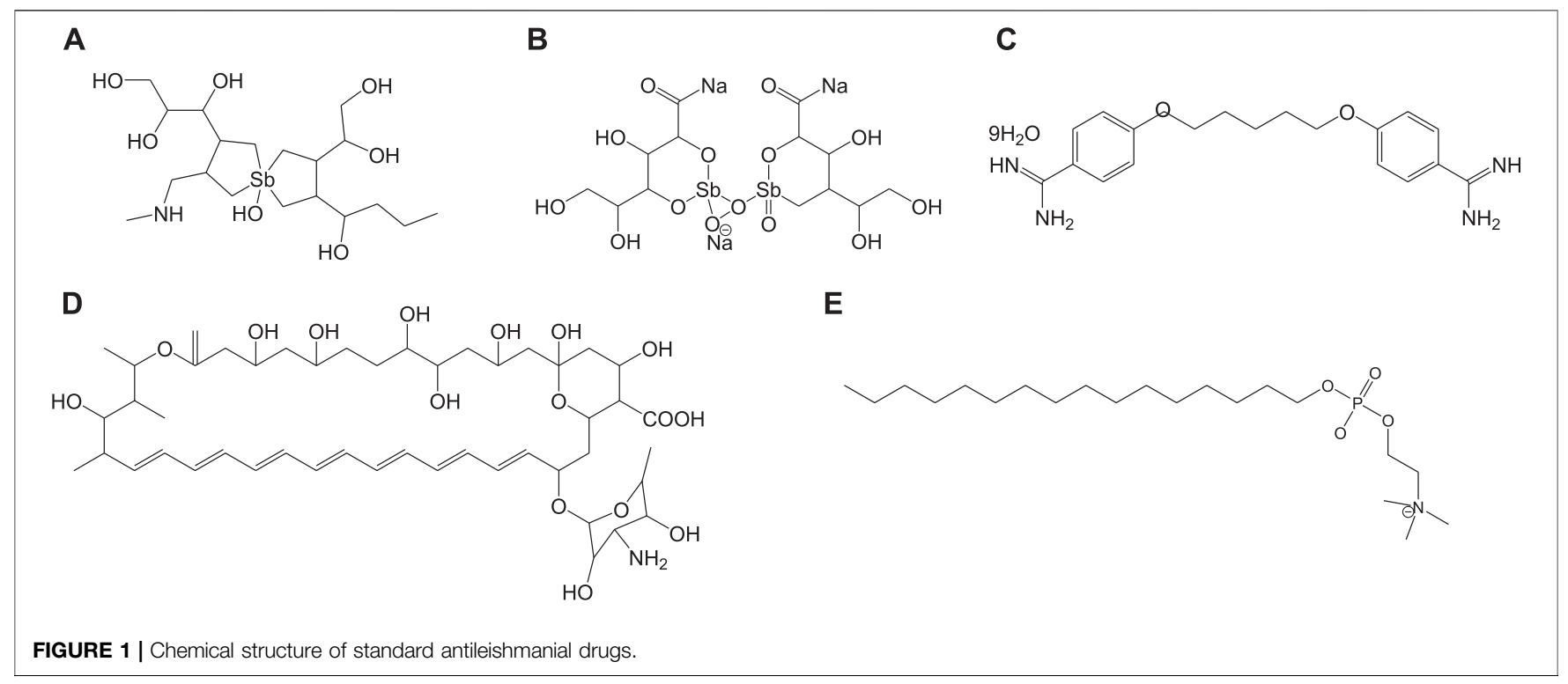

lesions that are formed due to cutaneous leishmaniasis (Yanik et al., 2004). These patients were found to have a low quality of life with symptoms of depression, high anxiety, and low body image satisfaction (Chahed et al., 2016). The currently available antileishmanial drugs to treat leishmaniasis are associated with several side effects, toxicity, and drug resistance.

\section{Standard Anti-Leishmanial Drugs}

Currently used antileishmanial drugs include pentavalent antimonials, pentamidine, amphotericin $\mathrm{B}$, and miltefosine and are known to target different metabolic pathways as discussed in Table 1. Figure 1 depicts the chemical structures of standard drugs reported in the literature to treat leishmaniasis namely: 1a (meglumine antimoniate or Glucantime ${ }^{\circledR}$ ) and $\mathbf{1 b}$ (sodium stibogluconate or Pentostam ${ }^{\circledR}$ ), 1 c (pentamidine), 1d (amphotericin B), and 1e (miltefosine). To date, the pentavalent antimonials are used for the treatment of all the three clinical forms of leishmaniasis. Some examples of pentavalent antimonials include 1a and 1b (Goodwin, 1995) (Figure 1). During the last century, antimony (III) potassium tartrate (tartar emetic) was used in the treatment of mucocutaneous leishmaniasis, which was then proved to be effective for visceral leishmaniasis in Africa (Cole, 1944), followed by its interruption in clinical usage due to severe side effects. In the 1940s, less toxic pentavalent antimony [Sb(V)] complexes (Berman, 1997) that includes $\mathbf{1 a}$ and $\mathbf{1 b}$ were reported to be more effective (20 $\mathrm{mg}$ of $\mathrm{Sb} / \mathrm{kg} /$ day for 20-30 days). There are two main models that describe the mechanism of action of these pentavalent antimonials in the treatment of leishmaniasis. The first model involves a prodrug concept, in which $\mathrm{Sb}(\mathrm{V})$ gets reduced to $\mathrm{Sb}$ (III), as observed in several in vivo studies (Burguera et al., 1993; Shaked-Mishan et al., 2001), to exhibit antileishmanial activity. Studies have suggested the involvement of thiols like trypanothione, cysteine, and cysteinylglycine or glutathione preferably in the amastigotes (dos Santos Ferreira et al., 2003), along with the involvement of enzymes that are specific to parasites like thiol-dependent reductase/antimoniate reductase (Zhou et al.,
2004). In the second model, $\mathrm{Sb}(\mathrm{V})$ itself was shown to possess antileishmanial activity, by forming complexes with ribose containing molecules and by inhibiting the type I DNA topoisomerases of $L$. donovani (Chakraborty and Majumder, 1988; Lucumi et al., 1998; Demicheli et al., 2002; Walker and Saravia, 2004). Due to affordability and high cure rate, these pentavalent antimonials have found their use as the first-line therapeutics for leishmaniasis.

Pentamidine (1c) was previously available in two forms: pentamidine methanesulfonate and pentamidine isethionate salt (Ghorbani and Farhoudi, 2018). Currently, pentamidine methane sulfonate formulations are not available but pentamidine isethionate is still in use. Treatment of cutaneous leishmaniasis using pentamidine mesylate and pentamidine isethionate is reported with nearly $90 \%$ cure rate without relapse of infection (Lai et al., 2002). No serious side effects except for respiratory tract problems were observed in patients treated with pentamidine isethionate. 1c of dosage, $2 \mathrm{mg} / \mathrm{kg}$ every other day for a total of seven injections, was proved to be effective against $80 \%$ of patients (in Colombia) for the treatment of cutaneous leishmaniasis (Soto-Mancipe et al., 1993). On comparison of 1c with 1a against the treatment of leishmaniasis caused by L. braziliensis, 1c was less effective than 1a (in Peru) (Andersen et al., 2005). Although its mechanism of action is not well known, the 1c compounds are found to enter L. donovani via the transporters of arginine and polyamine (Kandpal and Tekwani, 1997). This drug was reported to accumulate in the mitochondria (Mukherjee et al., 2006), by decreasing mitochondrial membrane potential and inhibit mitochondrial topoisomerase II (Basselin et al., 1996). The drug resistance in case of $\mathbf{1 c}$ was due to more drug efflux and reduced uptake of the drugs through the involvement of intracellular ABC protein PRP1 (pentamidine resistance protein 1 (Coelho et al., 2007). Amphotericin B (1d) is another choice of treatment for leishmaniasis in cases where resistance to pentavalent antimonials was observed. $1 \mathbf{d}$ is a polyene antifungal compound (fungizone, $\mathrm{C}_{47} \mathrm{H}_{73} \mathrm{NO}_{17}$ ) that targets sterol pathway, 
mainly ergosterols present in the cell membrane of the parasite (Purkait et al., 2012). The mechanism of action of $\mathbf{1 d}$ involves the formation of pores or channels on the lipid bilayer membranes of the targeted host cells (Baginski et al., 1997; Neumann et al., 2009). The channels or pores thus created by the membrane active drug $\mathbf{1 d}$ lead to influx of ions/solutes, thereby causing cell death. Membrane sterols are necessary for $\mathbf{1 d}$ to interact and form these channels/pores on the membrane (Hartsel and Bolard, 1996; Cohen, 2010). There are different formulations of 1d, for instance, amphotericin B lipid complex or ABLC (Abelcet), liposomal amphotericin B or L-AmB (AmBisome), amphotericin $\mathrm{B}$ colloidal dispersion, or $\mathrm{ABCD}$ (amphocil and amphotec) (Hamill, 2013). ABLC is composed of amphotericin B bound to two lipids, namely, L-a-dimyristoyl phosphatidylcholine (DMPC) and L- $\alpha$-dimyristoyl phosphatidylglycerol (DMPG), and has a therapeutic dosage of $5 \mathrm{mg} / \mathrm{kg} /$ day. ABLC is the largest among these three lipid molecules and was shown to be less effective than the amphotericin $\mathrm{B}$ deoxycholate in the stimulation of proinflammatory signaling molecules (Arning et al., 1995; Simitsopoulou et al., 2005). L-AmB was proven to be successful against visceral leishmaniasis, with a dosage level of 3-6 mg/kg/day (Davidson et al., 1991; Boswell et al., 1998). With a single dose of $\mathrm{L}-\mathrm{AmB}$, the concentration of the drug in plasma exceeds the concentration achieved by the conventional amphotericin B deoxycholate (Meyerhoff, 1999; Walsh et al., 2001), whereas in case of ABCD (with amphotericin B and cholesteryl sulfate, $3-4 \mathrm{mg} / \mathrm{kg} /$ day dosage), the concentration in plasma was less than that maintained by the conventional drug amphotericin B deoxycholate (Herbrecht et al., 1999; Hamill, 2013). Liposomal amphotericin B is an FDA-approved drug for the treatment of visceral leishmaniasis, which is usually administered through intravenous infusion.

Miltefosine (1e) or hexadecylphosphocholine (Impavido ${ }^{\circledR}$ ) is an alkyl phospholipid and an oral drug that is used for the treatment of all three forms of leishmaniasis. These compounds are phosphocholine analogs used for oral treatment against visceral leishmaniasis disease (Sundar and Olliaro, 2007; Dorlo et al., 2012b). 1e which works by targeting the cell membrane proteins/signaling pathways of the parasites induces cytotoxicity, ultimately leading to apoptosis. With the intake of $100 \mathrm{mg}$ of miltefosine/day (around $2.5 \mathrm{mg} / \mathrm{kg}$ of body weight/day) for a month, high efficacy with $97 \%$ cure rate was reported (Jha et al., 1999). However, in the same study, side effects like mild-tomoderate gastrointestinal problems were observed. The mechanism of action of $\mathbf{1 e}$ is not very clear, although different modes of actions have been proposed by several studies. Induced apoptosis-mediated cell death of the parasites (L. donovani), based on nuclear DNA condensation and fragmentation, was proposed (Verma and Dey, 2004). 1e was given as a monotherapy to treat cutaneous or visceral leishmaniasis with a dosage of $2.5 \mathrm{mg} / \mathrm{kg} /$ day for a total of 28 days (Dorlo et al., 2012b). 1e, initially an anticancer drug, was reported to have similar molecular modes of action against both the Leishmania spp. and the cancer cells in humans, which is mainly through apoptosis (Paris et al., 2004), lipid metabolism (Rakotomanga et al., 2007), and immunomodulatory effects (Liu et al., 2009; Wadhone et al., 2009). However, this drug also has the drawback of renal toxicity and is teratogenic, and not suitable to treat pregnant women. 1e analogs included two series of ether phospholipids: 1) cyclohexylidene or cyclopentadecylidene substituted ether phospholipids with $\mathrm{N}, \mathrm{N}, \mathrm{N}$ trimethylammonium or $N$-methylpiperidino or $N$-methylmorpholine head groups and 2) rigid head groups in combination with cycloalkylidene moieties in the lipid portion were reported to be 1.5 to 62 times more potent than miltefosine (Calogeropoulou et al., 2008). An alkyl phosphocholinedinitroaniline hybrid molecule was reported to be effective against promastigotes and intracellular amastigotes form of $L$. amazonensis and more selective than miltefosine (Godinho et al., 2013). Another study showed that a new series of 2-[3-(2alkyloxy-ethyl)-adamantan-1-yl]-ethoxy substituted ether phospholipids possessed antiparasitic activity with respect to the 2-alkyloxy substituent and were less cytotoxic compared to miltefosine (Papanastasiou et al., 2010).

\section{Emerging Drug Targets and Drugs Against Leishmaniasis \\ Nucleoside Analogs and Purine Salvage Pathway as Drug Targets}

The parasitic protozoan Leishmania lacks enzymes that are necessary for de novo synthesis of purine nucleotides. Usually, they are compensated by obtaining purine bases from the mammalian host cells via purine salvage system. Here, nucleoside transporters play vital roles in translocating purine bases through the cell surface of parasites.

The parasitic transporters are found to be unique compared to the transporters in the mammalian cells, in terms of substrate specificity. There are various pathways for nucleoside uptake with several purine/pyrimidine transporters involved such as LdNT1 and LdNT2, which are well studied (Vasudevan et al., 1998; Carter et al., 2000). Selectively targeting these transporters is difficult but it still remains a potential target, as they can uptake even toxic analogs of nucleosides that inhibit the cell growth of parasites.

Apart from these transporters, there are significant enzymes in the purine salvage pathway that include phosphoribosyl transferases. Purine analogs like allopurinol are known to inhibit phosphoribosyl transferases and are effective against parasites (Martinez and Marr, 1992). Allopurinol is effective against canine leishmaniasis but poses pharmacokinetic safety issues in case of humans (Yasur-Landau et al., 2016). In vitro studies have revealed a reduction in intramacrophagic amastigotes of L. infantum with the use of nucleoside analogs like immucillins (Freitas et al., 2015a). Immucillins or the synthetic deazapurine nucleoside analogs that include ImmA (IA), ImmH (IH), and SerMe-ImmH (SMIH) and their respective chemical structures are given in Figure 2 (Freitas et al., 2015b).

Another important enzyme in the purine salvage pathway includes the nucleoside diphosphate kinases (NDKs). An analog of a multitargeted receptor tyrosine kinase (RTK) inhibitor (Chow and Eckhardt, 2007) and a pyrrole-indolinone compound (Vieira et al., 2017) was reported, which binds 
<smiles>Nc1ncnc2c(C3NC(CO)C(O)C3O)c[nH]c12</smiles>

ImmA (IA)<smiles>O=c1[nH]cnc2c(C3NC(CO)C(O)C3O)c[nH]c12</smiles>

ImmH (IH)<smiles>O=c1[nH]cnc2c(CNC(CO)CO)c[nH]c12</smiles>

SerMe-ImmH (SMIH)

FIGURE 2 | Immucillines, the nucleoside analogs as hit candidates against leishmaniasis.

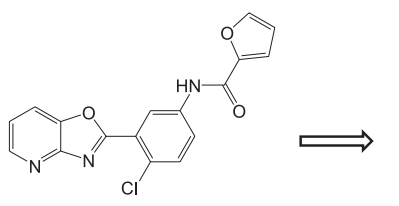

GNF5343 (hit from screen)

L. donovani $\mathrm{EC}_{50}=7.3 \pm 0.5 \mu \mathrm{M}$

T. brucei $\mathrm{EC}_{50}=150 \pm 7.5 \mu \mathrm{M}$

T. cruzi $\mathrm{EC}_{50}=7.5 \pm 0.8 \mu \mathrm{M}$

$3 \mathrm{~T} 3 \mathrm{CC}_{50}=7.3 \pm 0.8 \mu \mathrm{M}$

Macrophage $\mathrm{CC}_{50}>50 \mu \mathrm{M}$

$\mathrm{F}>50 \%$

$\mathrm{CL}=\mathrm{N} \mathrm{D}$

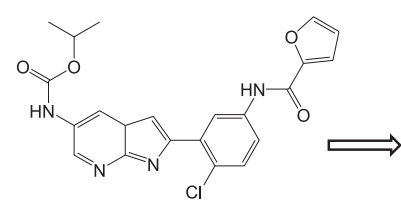

GNF2636

L. donovani $\mathrm{EC}_{50}=350 \pm 7.1 \mu \mathrm{M}$

T. brucei $\mathrm{EC}_{50}=79 \pm 2.9 \mu \mathrm{M}$

T. cruzi $\mathrm{EC}_{50}=55 \pm 12 \mu \mathrm{M}$

$3 \mathrm{~T} 3 \mathrm{CC}_{50}=9.0 \pm 0.9 \mu \mathrm{M}$

Macrophage $\mathrm{CC}_{50}=14.2 \pm 2.1 \mu \mathrm{M}$

$\mathrm{F}=\mathrm{N} \mathrm{D}$

$\mathrm{CL}=\mathrm{N} \mathrm{D}$

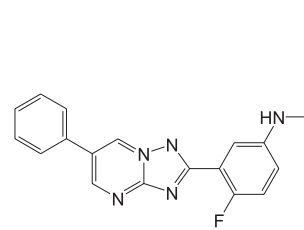

GNF3849

L. donovani $\mathrm{EC}_{50}=71.3 \mu \mathrm{M}$

T. brucei $\mathrm{EC}_{50}=22 \pm 2.0 \mu \mathrm{M}$

T. cruzi $\mathrm{EC}_{50}=16 \pm 0.9 \mu \mathrm{M}$

$3 \mathrm{~T} 3 \mathrm{CC}_{50}=5.0 \pm 1.3 \mu \mathrm{M}$

Macrophage $\mathrm{CC}_{50}=9.3 \pm 1.7 \mu \mathrm{M}$

F> $34 \%$

$\mathrm{CL}=2.5 \mathrm{~mL}$ “mm"”'kg”

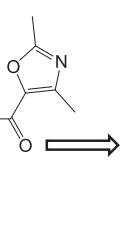

(1)

GNF6702

L. donovani $\mathrm{EC}_{50}=18 \pm 1.8 \mu \mathrm{M}$

T. brucei $\mathrm{EC}_{50}=70 \pm 1.5 \mu \mathrm{M}$

T. cruzi $\mathrm{EC}_{50}=120 \pm 1.5 \mu \mathrm{M}$

$3 \mathrm{~T} 3 \mathrm{CC}_{50}=20 \mu \mathrm{M}$

Macrophage $\mathrm{CC}_{50}>50 \mu \mathrm{M}$

F $>34 \%$

$\mathrm{CL}=2.0 \mathrm{~mL}$ "mm"'"kg"

$\mathrm{EC}_{50}$ and $\mathrm{CC}_{50}-50 \%$ inhibitory concentration

$\mathrm{F}$ - Oral availability in animal model after single dosage administration $\mathrm{CL}$ - Plasma clearance after single intravenous dosage

ND - Not determined

FIGURE 3 | Chemical evolution of proteasome targeting triazolopyrimidine scaffold inhibitors that act by inhibiting the activity of chymotrypsin protease.

A

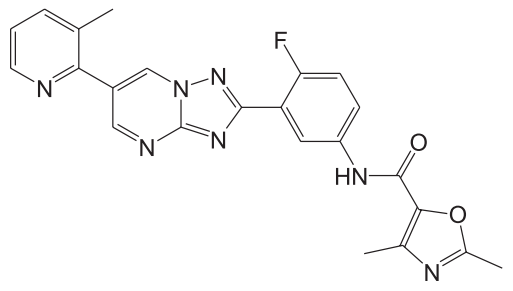

B<smiles>O=C(Nc1ccc(F)c(-c2ccn3c(N4CCOCC4)cnc3n2)c1)N1CCCC1</smiles>

FIGURE 4 | Compounds that inhibit $\beta 5$ subunits of proteasome.

NDK of L. major and exhibits antileishmanial activity in vitro. The latter drug was reported to possess potency and efficacy similar to that of the drug amphotericin B. The authors have suggested the use of this compound as a scaffold to develop new inhibitors against NDKs of Leishmania spp. (Vieira et al., 2017).

Though pyrimidine is synthesized by both de novo and through pyrimidine salvage pathway, enzymes of this pathway as well as the pyrimidine analogs are regarded as promising drug targets against Leishmania (Alzahrani et al., 2017). Recently, in vitro studies revealed the use of pyrimidine analogs, cytarabine, and 5-fluorouracil and two purine analogs, azathioprine and 6-mercaptopurine, against the growth of promastigote and amastigote forms of $L$. donovani and $L$. infantum (Azzouz and Lawton, 2017). Out of these four 


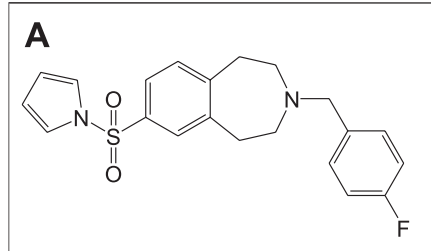

$$
\begin{gathered}
\mathrm{IC}_{50}=3.16 \mu \mathrm{M} \\
\text { Selectivity index }=10
\end{gathered}
$$

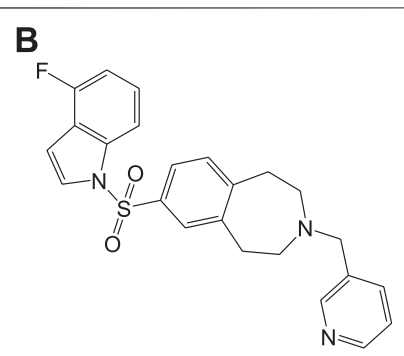

$\mathrm{IC}_{50}=2.00 \mu \mathrm{M}$

Selectivity index $=15.85$
FIGURE 5|Benzazepane-based hit compounds that act as inhibitors by targeting Leishmania inositol phosphorylceramide synthases.

analogs, cytarabine and 5-fluorouracil were efficient against the promastigote stage of parasites and 5-fluorouracil and azathioprine were effective against the intracellular amastigotes. Here 5-fluorouracil was found to be highly efficient against both stages of parasites by inducing cytoplasmic vacuolization, causing damage to mitochondria, and subsequently damaging the kinetoplast and death of the parasites.

\section{Kinetoplastid Proteasome Inhibition}

A selective (20S) proteasome inhibitor GNF6702 (Khare et al., 2016) that has evolved through phenotypic hit has proved proteasomes as a promising target for the treatment of infections by kinetoplastid parasites (Crunkhorn, 2016) including T. cruzi, Leishmania species, and T. brucei. The triazolopyrimidine scaffold of GNF6702 exhibited antiparasitic activity by inhibiting chymotrypsin protease activity. Figure 3 depicts the evolution of triazolopyrimidine scaffold drugs. The mode of action of this drug was known to occur by noncompetitive mode, without hindering the mammalian proteasomes or cells.

Recently, a structurally related proteasome inhibitor, 4a (LXE408) which is at present in phase 1 human clinical trials (Nagle et al., 2020) was reported. A novel mode of noncompetitive binding drug compound $4 \mathbf{a}$ with specific $\beta 5$ proteasome was also reported (Figure 4). Oral administration of compound 4a was reported to have high efficacy in infected mouse models in its preclinical studies and is currently tested for its safety and tolerability in phase I clinical trials.

Another potential antileishmanial compound $\mathbf{4 b}$ (Wyllie et al., 2019) was reported in the literature and its chemical structure is shown in Figure 4. The activity of this compound was verified against different clinically significant parasites like $L$. donovani, $L$. infantum, etc. This compound was reported to possess good pharmacokinetics, in vivo efficacy in infected mouse models, and comparable efficacy to the only approved oral antileishmanial drug miltefosine. The mechanism of action of this drug involves the profound inhibition of $\beta 5$ subunit of the proteasome via chymotrypsin-like activity in parasites. With consistent experimental data and high-resolution cryo-EM studies on this compound-proteasome complex, a new inhibitor site located between $\beta 4$ and $\beta 5$ proteasome subunits was reported. Due to the positive results in regard to safety and efficacy, this compound is taken further for human trials.

\section{Other Targets and Inhibitors Under Investigation}

Mitochondria, being one of the most important organelles for parasites, with their unique properties and proteins that differ from mammalian hosts, serve as a potential target for the development of therapeutics against parasitic infections like leishmaniasis (Tasbihi et al., 2019). Currently, the studies on mitochondria of parasites are limited; however, with the available information, chemotherapeutic approaches are being developed against the mitochondria of parasites (Villa-Pulgarín et al., 2017). For instance, chalcones are reported as potential lead compounds against leishmaniasis which target the mitochondrial structure (Zhai et al., 1995; Zhai et al., 1999) and function in the parasites, followed by the inhibition of fumarate reductase (Chen et al., 2001).

Mitochondrial cytochrome bc 1 plays a vital role in electron transport chain and is reported as a potential drug target. Endochin-like quinolones (ELQs) were studied to show toxicity against amastigote forms of $L$. donovani and $L$. mexicana targeting cytochrome bc 1 (Stickles et al., 2015; Ortiz et al., 2016). Hydroxynaphthoquinone buparvaquone has also been reported to be active against cytochrome bc 1, which inhibits electron transport, ATP synthesis, and parasite survival.

The Leishmania inositol phosphoryl ceramide (IPC) synthases (Norcliffe et al., 2018) are regarded as one of the potential drug targets. Modeling studies have revealed coumarin derivatives to possess antileishmanial activity, which were further validated by in vivo studies (Mandlik et al., 2016; Mandlik and Singh, 2016). In vitro studies with a new class of benzazepanes (5a and $\mathbf{5 b}$ ) are shown in Figure 5. Compounds $\mathbf{5 a}$ and $\mathbf{5 b}$ were reported to exhibit anti-Leishmania IPC synthase activity (Norcliffe et al., 2018). Similar compounds could be developed and studied to obtain new antileishmanial drugs. Apart from these, kinetoplastid topoisomerases (Das et al., 2008) and nuclear DNA primases (Bhowmik et al., 2020) of Leishmania species are suggested as other potential drug targets, for their structural diversity from mammalian hosts as well as their significance in DNA replication in the parasites.

Sitamaquine (6a, Figure 6) (8-aminoquinolines) (Yeates, 2002) is an antileishmanial oral drug, in which the molecular mechanism of action is yet to be understood. Although sitamaquine is reported to cause visual morphological changes in the parasite (LANGRETH et al., 1983), the specific target is yet to be identified. The interaction of sitamaquine with $L$. donovani revealed that the rapid diffusion of drug through the membrane accumulates in the cytosol by a process independent of energy or sterol in the parasite (Coimbra et al., 2010). Also, the interaction of $\mathbf{6 a}$ with the parasite membrane is transitory (Dueñas-Romero et al., 2007), and its efflux requires energy.

Paromomycin (6b, Figure 6) in the form of topical formulations was reported for leishmaniasis treatment. Paromomycin (paromomycin sulfate, $\mathrm{C}_{23} \mathrm{H}_{47} \mathrm{O}_{18} \mathrm{~S}$ ) drugs are aminoglycoside antibiotics, administered intramuscularly, to 


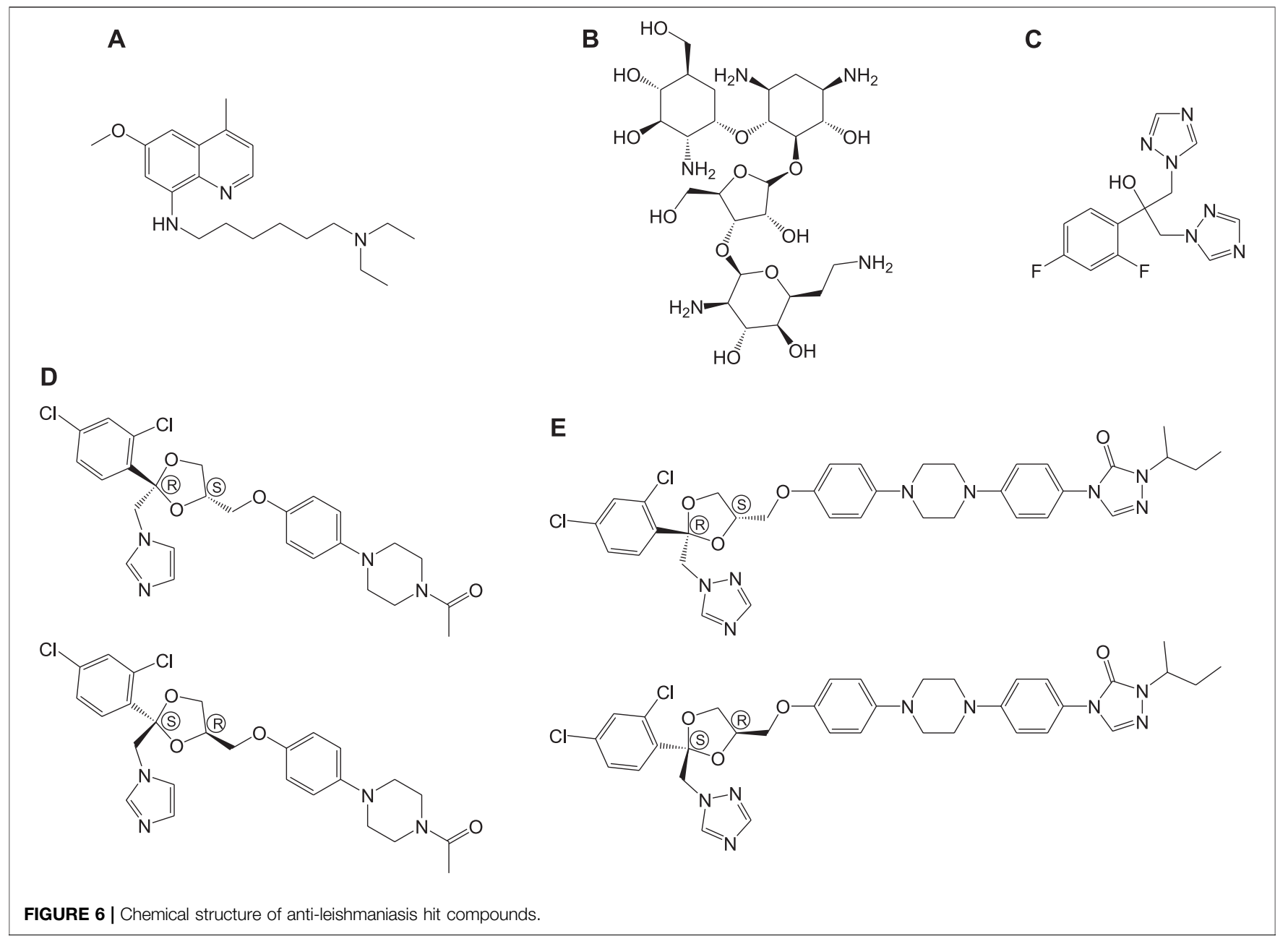

treat leishmaniasis in which mode of action is reported to involve mitochondria (Maarouf et al., 1997) and ribosomes (Maarouf et al., 1995) causing protein inhibition in the parasite. Another group of compounds used for the treatment of leishmaniasis are referred to as the azoles, for example, fluconazole (6c), ketoconazole $(\mathbf{6 d})$, and itraconazole $(\mathbf{6 e})$ as given in Figure 6 (Prates et al., 2017; Vera et al., 2018; Biswaro et al., 2019). However, the use of azoles was reported to show mixed results (Nagle et al., 2014; Galvao et al., 2017).

The enzymes, bifunctional dihydrofolate reductasethymidylate synthase, and pteridine reductase 1 in Leishmania spp. that are involved in the folate metabolic pathway were studied as targets for leishmaniasis treatment (Docampo et al., 2011). Dihydrofolate reductase enzyme was reported to be unique in the protozoan parasite Leishmania relative to that in the human host, thereby considering the enzyme as a promising target for selective drug design (Gilbert, 2002). In addition, pteridine reductase 1 inhibition was found to be essential to avoid the resistance to dihydrofolate reductase inhibitors. Chroman-4-one scaffold was reported to be a promising scaffold for the development of pteridine reductase 1 inhibitors against Leishmania spp., with low toxicity (Di Pisa et al., 2017). Structure-based optimization of piperidine-pteridine derivatives resulted in two compounds, methyl-1-(4-(((2,4diaminopteridin-6-yl)methyl)(2-ethoxy-2-oxoethyl)amino) benzoyl)piperidine-4-carboxylate and methyl 1-(4- $(((2,4-$ Diaminopteridin-6-yl)methyl)(2-hydroxyethyl)-amino)benzoyl) piperidine-4-carboxylate, with relatively high potency, enhanced binding affinity, and selectivity among other derivatives (Corona et al., 2012). Novel derivative compounds of arylnicotinic acids conjugated with aryl (thio)semicarbazides were also reported to be synthesized based on structure-guided approach targeting the enzyme pteridine reductase 1 (L. major) which was also proven to possess enhanced selectivity and antiamastigote activity relative to miltefosine (Eldehna et al., 2019).

\section{Liposomal Encapsulation and Nanoparticles in Anti-leishmanial Drugs}

Nanotechnology-based drug delivery or drug formulations were attempted to improve the efficacy and also to assure safety of drugs. The challenges in oral route of administration of pentamidine drugs were reported to be overcome by means of loading the drug in PLGA nanoparticles (Valle et al., 2019). Here, the nanoparticles were reported to be prepared by double emulsion method and in vitro/in vivo studies (infected BALB/c mice) were successful. These drug-loaded PLGA nanoparticles 
have shown a new perspective to drug administration with good pharmacological activity. Also, high efficacy has been reported with nanoformulations of amphotericin B (Manandhar et al., 2014), which is more safe and cost-effective and serves as an alternative to the existing conventional drug 1d. Topical nanoliposomal formulations were prepared to treat cutaneous leishmaniasis, with liposomes containing $0.1,0.2$, and $0.4 \% \mathbf{1 d}$ (Lip-AmB), out of which $0.4 \%$ Lip-AmB was found to possess longer stability for about 20 months at room temperature (Jaafari et al., 2019). These formulations were effective against the lesions in $L$. major-infected $B A L B / c$ mice and also showed inhibition of the promastigotes/amastigotes growth in vitro. Fungisome is a liposomal formulation marketed in India (Wijnant et al., 2018), with lipids and formulations different from that of the standard AmBisome. In a study with $L$. major-infected BALB/c murine model (cutaneous leishmaniasis infection), it was reported that fungisome at a dosage of $1 \mathrm{mg} / \mathrm{kg}$ revealed toxicity, whereas AmBisome was nontoxic. However, the antileishmanial activity was exhibited with $\sim 5-10 \mathrm{mg} / \mathrm{kg}$ of fungisome and also proved to be less efficacious when compared with AmBisome.

Artemisinin and its derivatives are another group of molecules that are reported to be effective for visceral leishmaniasis treatment. These are found to work by generating free radicals leading to apoptosis in parasites (Sen et al., 2010). In vivo studies in mice with nanoliposomal formulations of artemisinin were reported to reduce leishmanial intracellular infections (Ghaffarifar et al., 2015). Polymer (PLGA-poly (d,l-lactic-coglycolic acid))-based nanoparticles were also shown to act as carrier of the drug artemisinin, facilitating sustained release of the drug (in vitro studies) along with antileishmanial activity (ex vivo). These artemisinin-incorporated PLGA polymeric nanoparticles also exhibited reduction of parasites or antiparasitic activity (Want et al., 2014; Want et al., 2015; Want et al., 2017). The pros of using these drug-loaded nanoparticles include reduction of drug toxicity, enhanced hydrophilicity, and bioavailability. However, these nanoparticles have not attained the level of clinical trials due to the higher cost, lower drug load, and toxicity involved in the preparation stage. Also, the limited availability of reports on nanoparticles with antileishmanial activity necessitated the need for exploration in this field of research that can reach clinical trials.

A recent in vitro study involved the use of an FDA-approved drug for malaria treatment (Chavali et al., 2012), halofantrine, for leishmaniasis treatment. By liposomal encapsulation of halofantrine, called halolipo, the issues of hydrophobicity and cardiotoxicity of the halofantrine drug were overcome. Halolipo ( $\sim 20 \mathrm{~nm}$ diameter), on exposure to the protozoan parasite $L$. donovani (promastigotes), led to reduction in viable number of parasites. This could be due to ROS generation and depolarization of mitochondrial membrane of the parasites. Also, in vitro studies on the same confirm the selective reduction of viable parasites, dependency on drug concentration, and nontoxicity to mammalian host cells. However, in vivo studies ought to be performed with halolipo, so that this drug could be developed as an effective therapeutic for leishmaniasis in near future.

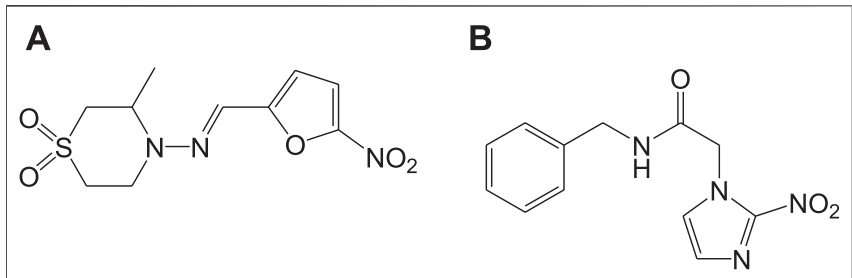

FIGURE 7 | Chemical structure of antichagasic nitro heterocyclic compounds.

Use of nanosilver has also been tested by several researchers as therapeutics for leishmaniasis. It was reported to possess higher potency as the size becomes smaller (Allahverdiyev et al., 2011a; Allahverdiyev et al., 2011b). Nanosilver is shown to cause DNA damage and generate free radicals in the parasites with increase in immunomodulatory effects in human cell lines (de Menezes et al., 2015). Selenium nanoparticles known to possess antimicrobial, anticancerous, and antioxidant properties were used to develop a novel approach to treat cutaneous lesions and were proven to exhibit antileishmanial activity in both in vivo and in vitro studies. Also, these nanoparticles exhibited significant potency against $L$. tropica (Shakibaie et al., 2015). Another interesting finding involved silver-doped titanium oxide (TiAg), formulated by green synthesis using essential oil from Nigella sativa which showed high antileishmanial activity against $L$. tropica and $L$. infantum (Allahverdiyev et al., 2013). This formulation was proven to be nontoxic with high potency for treatment of cutaneous leishmaniasis. Another nanoformulation based on the combination of the miltefosine drug (Figure 1) with curcumin nanoformulation was reported (Tiwari et al., 2017) to possess enhanced antileishmanial activity both in vitro and in vivo.

\section{CHAGAS DISEASE}

Chagas disease, also called American trypanosomiasis, is one of the NTDs, which is endemic mainly in Latin America and spreads in European countries, Australia, Japan, Canada, and southern parts of the United States. Chagas disease is caused by a parasite named T. cruzi, a hemoflagellate protozoan of Kinetoplastida order and Trypanosomatidae family, which can occur in two phases, acute and chronic. This disease was discovered by a physician Carlos Chagas, who had stated during the initial period that there was no specific treatment for this disease, in his publication "Manual of Tropical and Infectious Diseases." In Chagas disease, the causative protozoan is Trypanosoma cruzi, from which the trypomastigote forms are transmitted to humans through insects that belong to the subfamily Triatominae. These infective trypomastigotes are present in the fecal matter of the bug and enter into the tissues of human host through the bitten wound and later develop into an intracellular replicative parasitic form of amastigotes. Other modes of transmission are through infected blood transfusion/organ transplantation and genetic transmission from mother to fetus. Chagas disease occurs 

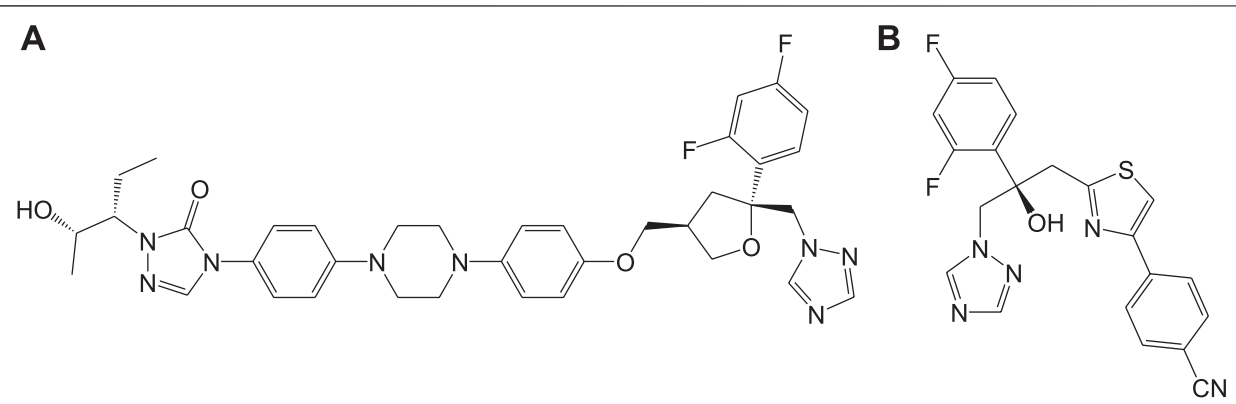

FIGURE 8 | Potent anti-Chagas azole-derived compounds that target sterol biosynthetic pathway.

mainly through two routes, congenital and oral. The congenital Chagas disease occurs throughout the world even in the nonendemic areas. The oral Chagas disease leads to acute disease outbreaks in the areas facing vectorial route interruptions (Sánchez and Ramãrez, 2013). Congenital Chagas disease is mostly asymptomatic but includes some nonspecific clinical manifestations like myocarditis, gastrointestinal problems, meningoencephalitis, anemia, low birth weight, jaundice, microencephaly, ocular lesions, etc. (Schijman, 2006; Punukollu et al., 2007). Around 30\% of these congenitally affected patients tend to develop symptomatic chronic phase of Chagas disease with cardiac and digestive problems (Rassi et al., 2010; Carlier et al., 2011). These patients possess lower possibility of developing cardiac problems relative to that in patients infected by vectorial route (Bern et al., 2011; Fabbro et al., 2014). In patients with oral Chagas disease infection, high mortality rate is observed in the first two weeks after infection followed by inflammation in the gastric mucosa which extends to proximate mesentery (Hoft et al., 1996). Clinical manifestations like myocarditis, acute heart failure, and meningoencephalitis are observed with orally infected Chagas disease (Punukollu et al., 2007; Shikanai-Yasuda and Carvalho, 2012). In case of acute infections through oral route, clinical features include abdominal pain, gastrointestinal tract bleeding, heart murmurs, palpitations, jaundice, nausea, vomiting, hepatomegaly, enteritis, and chest pain (WHO-ExpertCommittee, 2002; Andrade et al., 2014). During the 1960s, the therapeutic activity of nitrofurans in infected murines and humans was discovered but it had a low curative effect which stopped its further development. Moreover, their curative ability differed in geographic areas, potentially due to mutations/ variations in genetic strains of the parasites. These drugs were not effective against chronic cases of Chagas disease and include several serious side effects like anorexia, digestive manifestations, hypersensitivity, bone marrow depression, dermatitis with cutaneous eruptions, and peripheral polyneuropathy. The beginning of the 1980s marked the introduction of techniques like immunohistochemistry and PCR, which confirmed the association of parasites and their DNA with the inflammatory reactions resulting in pathological lesions in chronic Chagas disease. Several experimental studies (Morillo et al., 2015; Soy et al., 2015; Fernández et al., 2016) and clinical trials (Andrade et al., 2013; Chatelain, 2017) have been reported to show the significance of reducing the parasite load in chronic Chagas disease treatment and the associated chronic cardiomyopathy.

\section{Standard Anti-chagasic Drugs}

At present, Chagas disease is treated by the two nitro heterocyclic compounds that were discovered in 1960-1970, namely, nifurtimox (7a) and benznidazole (7b) (Maya Arango et al., 2010), and the chemical structures are shown in Figure 7.

These drugs work by accumulation of free radicals generated by means of the nitro groups, which further resulted in high antioxidant activities in T. cruzi, ultimately killing the parasites. As stated before, these drugs are effective only for acute cases of Chagas disease infection along with side effects.

\section{Emerging Drug Targets and Drugs Against Chagas Disease CYP51 Inhibitors}

Inhibitors of sterol biosynthetic pathway have been reported as one of the new drug targets for the treatment of Chagas disease. In particular, C14-ademethylase (CYP51) represents a potential drug target in which various inhibitors like azoles block the ergosterol biosynthesis and sterol C14-demethylase (CYP51) activities in the parasite. In vivo studies have revealed that the above compounds possess high potency of antichagasic activity along with good pharmacokinetic properties like longer half-life and large volume of distribution as compared to the previously existing drugs. Phase II clinical trials of the drugs (Figure 8), posaconazole $(\mathbf{8 a})$, and a prodrug of ravuconazole $(\mathbf{8 b})$ were reported to ensure safety, without sustained efficacy as single medications, in patients with chronic Chagas disease (Tarleton et al., 2014; Álvarez et al., 2015).

The other strategies involved variation in dosages and combination of drugs to improve the efficacy against Chagas disease. It was also reported that prolonged treatment with azole drugs like $\mathbf{8 a}$ is required for potent antichagasic activity. This idea is also validated by Guedes et al. (da Matta Guedes et al., 2004) in infected dogs with treatment using benznidazole or albaconazole which resulted in complete cure within 60 days of treatment and 90 days of treatment, respectively. This necessitates the consideration of individual dosage regimens, drug concentration, and treatment time for successful treatment. With the high efficacy of azole derivatives, researchers are 


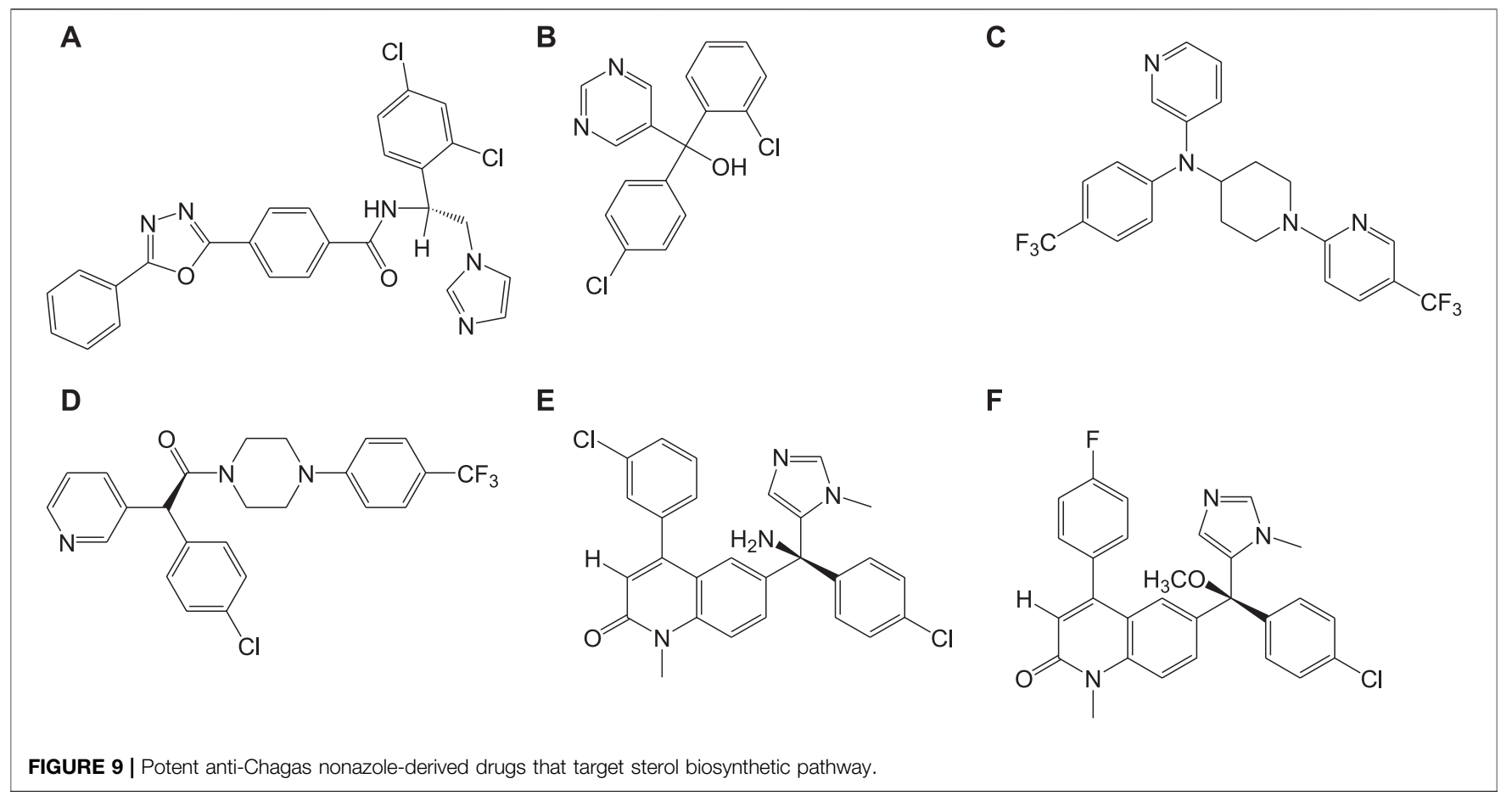

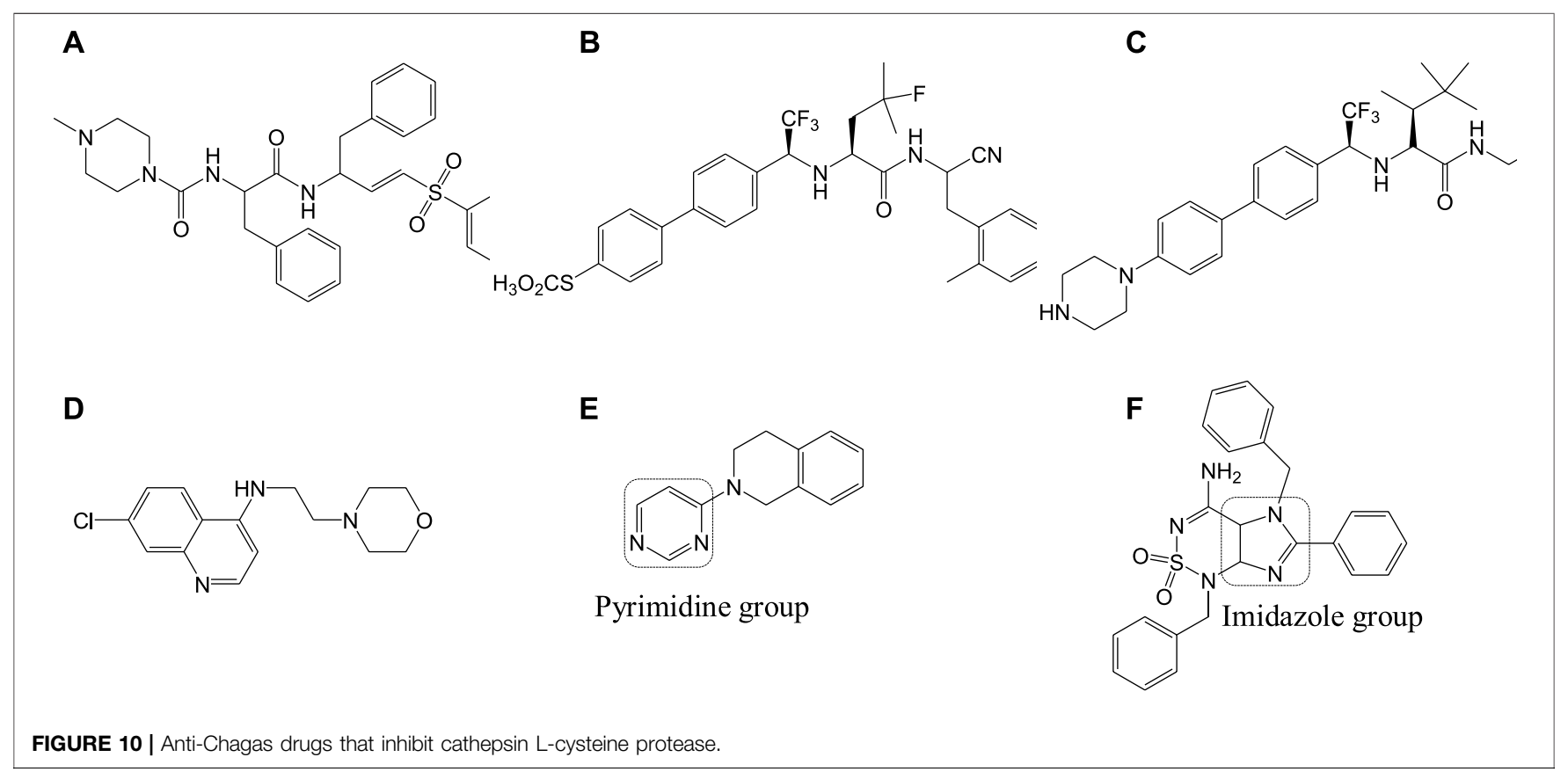

currently working on developing rational approaches for antichagasic therapeutics.

In vivo studies with nonazole derivative 9a for CYP51 inhibition have revealed variations in antichagasic activity with different parasitic strains. With a nonazole CYP51 inhibiting compound, fenarimol (9b) as scaffold, two other lead compounds 9c and 9d were developed which were reported to possess antichagasic activity similar to that of $\mathbf{8 a}$ and better than $\mathbf{7 b}$ (Keenan et al., 2013). Buckner et al. developed an analog of tipifarnib (9e), anticancer drug, in which farnesyltransferase inhibitory activity was eliminated and CYP51 inhibition was withheld (Buckner et al., 2012). This compound was found to be highly potent with antichagasic activity in mouse models but requires improvement in pharmacokinetic properties. Similarly, 


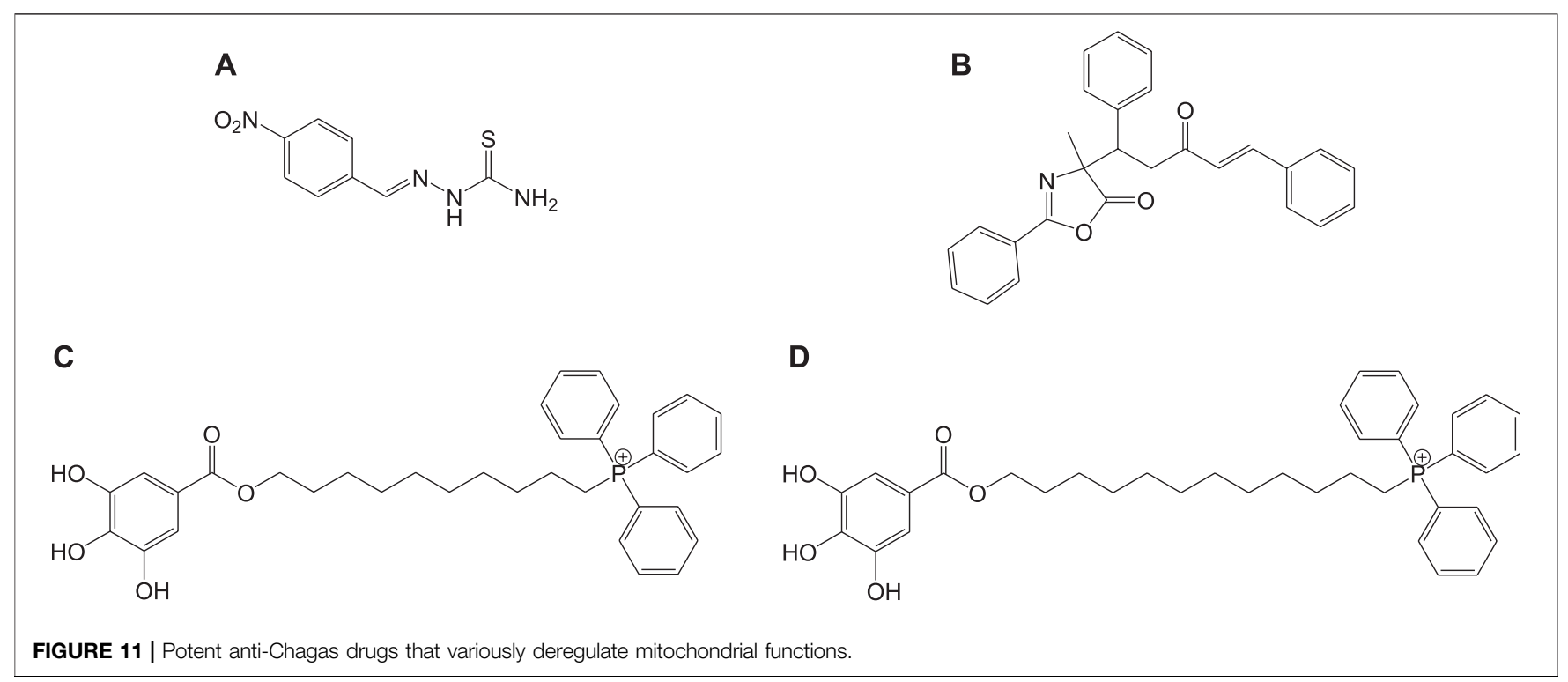

another compound 9f, an atropisomer evolved from 9e, was found to possess similar potency against $T$. cruzi. The chemical structures of nonazole-derived drugs that target the sterol biosynthetic pathway are shown in Figure 9.

\section{Cruzain Inhibitors}

Cruzipain or cruzain denotes cathepsin L-cysteine protease that performs proteolytic activity throughout all stages in the life of T. cruzi. Studies have reported the importance of this enzyme in various biological functions including evasion of the immune system and host-parasite interactions (Brak et al., 2010; Bahia et al., 2014). Inhibitors of this protease also serve as significant drug targets in Chagas disease therapeutics. Compound 10a, a vinyl sulfone, was rationally designed to selectively inhibit this cruzipain protease. This compound was reported to exhibit anti-T. cruzi activity in experimental mice models (immunocompetent and immunodeficient) infected with T. cruzi (Doyle et al., 2007). However, complete curability was not observed with compound 10a when tested on acutely infected (T. cruzi) dog models, but it was reported to reduce the myocardial damage (Barr et al., 2005). Compound 10a is currently in its advanced stages of preclinical studies, and also several other cruzipain inhibitor compounds with better potency and selective anti-T. cruzi activities are being developed (Brak et al., 2010; Ndao et al., 2014). Recently, two compounds $\mathbf{1 0 b}$ and 10c were identified by Ndao et al., which showed curability of 78 and $90 \%$, respectively, in acutely infected murines (Ndao et al., 2014). Several analogs of 8-chloro-N-(3-morpholinopropyl)-5Hpyrimido [5,4-b]indol-4-amine containing indole, pyrimidine, quinoline, aniline, and pyrrole groups were reported to be tested for antichagasic activity. Among the several derivatives, 4-aminoquinoline analogs, in particular compound 10d, were reported to have anticruzain activity along with antichagasic activity against T. cruzi (Tulahuen strain) with lower selectivity. Pyrimidine analog 10e was found to be highly active and selective for Chagas disease but lacked anticruzain activity (Schmidt and Krauth-Siegel, 2002). This implicates the need to understand the mechanism of action behind these compounds with in vivo studies (Arias et al., 2017; Vázquez et al., 2017). Also, several computational screening studies have revealed the synthesis and biological activities of several imidazole compounds. Among the various compounds identified, compound 10f (Rodrígues-Poveda et al., 2012) was shown to exhibit high anti-T. cruzi activity against three strains including Tulahuen 2, CL-clone B5, and Y. The structures of potent inhibitors that target cathepsin L-cysteine protease are given in Figure 10.

\section{Mitochondrial Deregulation Drugs}

Mitochondria are vital cell organelles that are involved in ATP synthesis, nutrient oxidation, cellular redox, calcium homeostasis, and apoptosis. It produces hydrogen peroxide as the main oxidative species for cellular signaling in cytosol, and deregulation of mitochondria causes an increase in reactive oxygen species, leading to cytotoxicity and cell death. T. cruzi possesses unique mitochondria containing kinetoplasts and compactly packed mitochondrial DNA that accounts for $30 \%$ of its entire genome, making mitochondria an important drug target for Chagas disease treatment. An in vitro study has investigated the antichagasic activity of 4nitrobenzaldehyde thiosemicarbazone (11a) (Figure 11), an S-limonene derivative, which showed potent activity against trypomastigotes and amastigotes of T. cruzi. Compound $\mathbf{1 1} \mathbf{b}$ was reported to deregulate mitochondria of the parasites by cytoplasmic vacuolization, reduction in membrane potential, and increased free radical generation (Britta et al., 2015). Another study evaluated four C-4 functionalized azalactone derivatives for antichagasic activity (de Azeredo et al., 2017). Among these derivatives, one compound 11c was found to possess three times more anti-T. cruzi activity compared to that of the antichagasic drug $\mathbf{7 b}$. Reduction in mitochondrial 

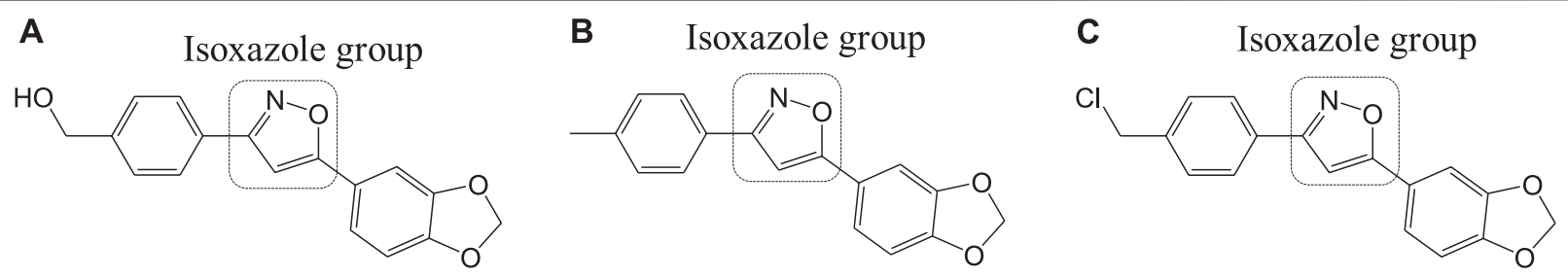

FIGURE 12 | Potent anti-Chagas isoxazole-derived drugs that target trypanothione reductase.<smiles>COc1cccc(Nc2c(C#N)cnc3ccc(Cl)cc23)c1</smiles>

FIGURE 13 | Quinoline derivative that inhibits heme peroxidation by forming heme-quinoline complex as potent antichagasic lead candidate.

membrane potential and size of epimastigotes was observed by flow cytometry and electron microscopy studies. It is recommended that these compounds could be used as a scaffold in the development of new therapeutic drugs for Chagas disease (de Azeredo et al., 2017). Yet another antichagasic agent was developed using gallic acid derivatives possessing lipophilic groups and triphenylphosphonium moiety that target the mitochondria of $T$. cruzi. Among these derivatives, relatively more potent compounds 11c and 11d compared to compound 7a were reported (Cortes et al., 2015). These compounds were also highly selective and formed pores on mitochondrial membrane by varying the membrane potential. Further new analogs with antichagasic activity can potentially be developed from these derivatives.

\section{Trypanothione Reductase}

Trypanothione reductase is another significant therapeutic target for Chagas disease treatment, mainly because of its unique presence in Trypanosomatidae family and not in mammalian cells (Krieger et al., 2000; Khan, 2007; Beig et al., 2015). The reduction of trypanothione disulphide to trypanothione occurs in the presence of NADPH and is catalyzed by the enzyme trypanothione reductase (Fairlamb et al., 1985; Bond et al., 1999; Krieger et al., 2000; Beig et al., 2015).

Different isoxazole analogs were reported to be synthesized by microwave irradiation, with structures based on the natural lignans, veraguensin, and grandisin which exhibited potent activities against $T$. cruzi (Tulahuen strain) trypomastigote forms in the circulating blood and amastigote forms within the cells (da Rosa et al., 2017). Three compounds 12a, 12b, and 12c (Figure 12) were found to be potent against amastigotes at concentrations lower than that reported for benznidazole derivatives but were inactive against trypomastigotes. By means of enzymatic assays, isoxazoles were reported to act independently on the enzyme trypanothione reductase. Recent studies have reported computationally screened and evaluated trypanothione reductase inhibitors against Chagas disease, which were obtained from natural products database (da Paixão and da Rocha Pita, 2019).

\section{Heme Peroxidation as Drug Target}

In general, heme or ferroprotoporphyrin plays a significant role in various biological processes including energy production, detoxification, respiration, oxygen transport, and antioxidant gene expression. Breakdown of heme is known to generate free radicals, which causes damage to DNA, proteins, lipids, and ultimately the cells. The requirement of heme in T. cruzi for multiplication of epimastigote forms by redox mechanism is stated as a potential drug target that can be blocked to possibly inhibit the epimastigotes (de Almeida Nogueira et al., 2011; Nogueira et al., 2017). Quinoline compounds are made of nitrogen heterocyclic groups that form complexes with heme and have been reported to possess activity against plasmodium, Leishmania, T. cruzi, bacteria, and also cancer (Eswaran et al., 2010; Ganguly et al., 2011; Muscia et al., 2011). Several derivatives of 4-arylaminoquinoline-3-carbonitrile were reported to exhibit anti-T. cruzi activity; in particular, compound 13 was found to be more active than compound $\mathbf{7 b}$, when complexed with hemin (Lechuga et al., 2016). The authors had reported enzymatic conversion of heme to biliverdin favoring oxygenase activity in parasites and also the complex formation of heme-quinoline compound $\mathbf{1 3}$ (Figure 13) leading to a reduction in heme levels followed by the generation of reactive oxygen species resulting in the death of parasites.

\section{Other Targets and Formulations for Anti-Chagas Drug Development}

T. cruzi depends on inherent sterols including ergosterol and its analogs for survival, where ergosterols play an important part in maintaining the plasma membrane (Urbina et al., 2002; Shang et al., 2014). Ergosterol requires squalene synthase for its biosynthesis, which catalyzes squalene formation by dimerization of two farnesyl pyrophosphate (FPP) molecules (Urbina et al., 2002). Researchers have found that inhibition of the squalene synthase can be a potential drug target for Chagas disease treatment. Inhibitors targeting squalene synthase were developed by several researchers (Chao et al., 2017) and are still in the process of investigation. Similarly, farnesyl diphosphate 
synthase (FPPS) in the mevalonate pathway is stated as a potential target for several parasitic diseases (Demoro et al., 2012; Ferrer-Casal et al., 2014). Inhibition of FPPS indirectly blocks the synthesis of farnesyl diphosphate, by blocking the synthesis of farnesyl pyrophosphate and geranylgeranyl pyrophosphate (Aripirala et al., 2012). Several bisphosphonate derivatives are under research against T. cruzi by FPPS inhibition, to obtain new therapeutic drugs for Chagas disease (Recher et al., 2013). T. cruzi contains four iron superoxide dismutases (FeSODs) formed in the mitochondria (TcSODA and C), cytosol (TcSODB1), and glycosomes (TcSODB1-2) (Piacenza et al., 2013), which are unique to these parasites and different from that in humans, thereby serving as potential targets (Mateo et al., 2008). These superoxide dismutases are known to neutralize toxicity generated by oxygen radicals (Temperton et al., 1998). Studies evaluating the antichagasic activity of potential drugs by inhibition of Fe-SOD were also reported; for instance, a series of derivatives of arylaminoketones were tested (Moreno-Viguri et al., 2016) and shown to exert antichagasic activity by means of Fe-SOD inhibition. It is confirmed by analyzing the $1 \mathrm{H}$ Magnetic Nuclear Resonance $\left({ }^{1} \mathrm{H}\right.$ NMR) chemical shifts of excreted metabolites from the cultures of epimastigotes of $T$. cruzi Arequipa strain that was treated with test compounds.

Nanostructure formulations with trypanocidal activity were developed to lower the toxicity of drugs like $\mathbf{7 b}$. Nanoparticles including nanostructured lipid carriers, liposomes, quatsomes, solid lipid nanoparticles, and cyclodextrins were evaluated (Scalise et al., 2016; Vinuesa et al., 2017). Cyclodextrinsbenznidazole complexes were reported to be relatively lower than that of benznidazole in its free form (Vinuesa et al., 2017).

\section{CONCLUSION}

Although the spread of both leishmaniasis and Chagas disease is under control, the threat still exists because of limited therapeutics and increasing incidents of drug resistance. Many drugs that are available to treat these diseases possess serious side effects and existing diversity among the causing parasites. Moreover, many drugs are active only in the acute phase of the disease. Herein, the various therapeutic strategies, drug targets, and drugs for leishmaniasis and Chagas disease were discussed. The significance of these two diseases based on the economic burden and the disability caused by them has opened

\section{REFERENCES}

Adams, E. R., Versteeg, I., and Leeflang, M. M. (2013). Systematic review into diagnostics for post-Kala-Azar dermal leishmaniasis (PKDL). J. Trop. Med. 2013 (8), 150746. doi:10.1155/2013/150746

Allahverdiyev, A. M., Abamor, E. S., Bagirova, M., Baydar, S. Y., Ates, S. C., Kaya, F., et al. (2013). Investigation of antileishmanial activities of $\mathrm{Tio}_{2}{ }^{@} \mathrm{Ag}$ nanoparticles on biological properties of L. Tropica and L. Infantum parasites, in vitro. Exp. Parasitol. 135 (1), 55-63. doi:10.1016/j.exppara.2013. 06.001

Allahverdiyev, A. M., Abamor, E. S., Bagirova, M., and Rafailovich, M. (2011a). Antimicrobial effects of $\mathrm{TiO}_{2}$ and $\mathrm{Ag}_{2} \mathrm{O}$ nanoparticles against drug-resistant new avenues for novel therapeutics and drug targets. The presently employed strategies like novel drug developments and the use of a combination or repurposed drugs have been discussed briefly besides their advantages and future scopes. For leishmaniasis, standard drugs like pentavalent antimonials, pentamidine, amphotericin B, and miltefosine that target various metabolic pathways are discussed with their mechanism of action, advantages over other drugs, and limitations on their use. Various drugs that target the purine salvage pathway, purine and pyrimidine analogs, and their efficiencies at various stages of the pathogens cycle are also reviewed. The role of nanotechnology, various proteasome inhibitors, and enzymes that are under investigation as potential targets for leishmaniasis are also reviewed. With Chagas disease, various standard drugs like nifurtimox and benznidazole and their mechanism of action towards killing the parasites are discussed. Various inhibitors for Chagas disease that target CYP51, cruzain, trypanothione reductase, mitochondrial functions, heme peroxidation, etc. are also discussed. The recently developed nanostructure formulations including nanostructured lipid carriers, liposomes, quatsomes, solid lipid nanoparticles, and cyclodextrins that can reduce the toxic effects of anti-Chagas drugs are detailed.

This review details the advancements towards drug development. In recent years, it has been observed that the sensitivity of the available standard drugs varied in clinical samples over years, due to acquired resistance. Therefore, new therapies and strategies also need to be identified and implemented to prevent the emergence of new drug-resistant strains. Combination therapies and improved diagnosis could play key roles in disease management approaches.

\section{AUTHOR CONTRIBUTIONS}

All authors listed have made a substantial, direct, and intellectual contribution to the work and approved it for publication.

\section{ACKNOWLEDGMENTS}

The authors gratefully acknowledge Vellore Institute of Technology, Vellore and Chennai campus, for the support and encouragement.

bacteria and leishmania parasites. Future Microbiol. 6 (8), 933-940. doi:10. 2217/fmb.11.78

Allahverdiyev, A. M., Abamor, E. S., Bagirova, M., Ustundag, C. B., Kaya, C., Kaya, F., et al. (2011b). Antileishmanial effect of silver nanoparticles and their enhanced antiparasitic activity under ultraviolet light. Int. J. Nanomed. 6, 2705. doi:10.2147/IJN.S23883

Alvar, J., Velez, I. D., Bern, C., Herrero, M., Desjeux, P., Cano, J., et al. (2012). Leishmaniasis worldwide and global estimates of its incidence. PLoS One 7 (5), e35671. doi:10.1371/journal.pone.0035671

Álvarez, G., Varela, J., Cruces, E., Fernández, M., Gabay, M., Leal, S. M., et al. (2015). Identification of a new amide-containing thiazole as a drug candidate for treatment of Chagas' disease. Antimicrob. Agents Chemother. 59 (3), 1398-1404. doi:10.1128/AAC.03814-14 
Alzahrani, K. J., Ali, J. A., Eze, A. A., Looi, W. L., Tagoe, D. N., Creek, D. J., et al. (2017). Functional and genetic evidence that nucleoside transport is highly conserved in Leishmania species: implications for pyrimidine-based chemotherapy. Int. J. Parasitol. Drugs Drug Resist. 7 (2), 206-226. doi:10. 1016/j.ijpddr.2017.04.003

Andersen, E. M., Cruz-Saldarriaga, M., Llanos-Cuentas, A., Luz-Cjuno, M., Echevarria, J., Miranda-Verastegui, C., et al. (2005). Comparison of meglumine antimoniate and pentamidine for peruvian cutaneous leishmaniasis. Am. J. Trop. Med. Hyg. 72 (2), 133-137. doi:10.4269/ajtmh.2005.72.133

Andrade, D. V., Gollob, K. J., and Dutra, W. O. (2014). Acute chagas disease: new global challenges for an old neglected disease. PLoS Negl. Trop. Dis. 8 (7), e3010. doi:10.1371/journal.pntd.0003010

Andrade, M. C., Oliveira Mde, F., Nagao-Dias, A. T., Coelho, I. C., Candido Dda, S., Freitas, E. C., et al. (2013). Clinical and serological evolution in chronic Chagas disease patients in a 4-year pharmacotherapy follow-up: a preliminary study. Rev. Soc. Bras Med. Trop. 46 (6), 776-778. doi:10.1590/ 0037-8682-1646-2013

Arias, D. G., Herrera, F. E., Garay, A. S., Rodrigues, D., Forastieri, P. S., Luna, L. E., et al. (2017). Rational design of nitrofuran derivatives: synthesis and valuation as inhibitors of Trypanosoma cruzi trypanothione reductase. Eur. J. Med. Chem. 125, 1088-1097. doi:10.1016/j.ejmech.2016.10.055

Aripirala, S., Szajnman, S. H., Jakoncic, J., Rodriguez, J. B., Docampo, R., Gabelli, S. B., et al. (2012). Design, synthesis, calorimetry, and crystallographic analysis of 2-alkylaminoethyl-1, 1-bisphosphonates as inhibitors of Trypanosoma cruzi farnesyl diphosphate synthase. J. Med. Chem. 55 (14), 6445-6454. doi:10.1021/ jm300425y

Arning, M., Kliche, K., Heer-Sonderhoff, A., and Wehmeier, A. (1995). Infusionrelated toxicity of three different amphotericin B formulations and its relation to cytokine plasma levels: infusions-assoziierte toxizität dreier amphotericin Bformulierungen und ihre beziehung zu zytokin-plasmaspiegeln. Mycoses 38 (11-12), 459-465. doi:10.1111/j.1439-0507.1995.tb00020.x

Azzouz, S., and Lawton, P. (2017). In vitro effects of purine and pyrimidine analogues on Leishmania donovani and Leishmania infantum promastigotes and intracellular amastigotes. Acta Parasitol. 62 (3), 582-588. doi:10.1515/ap2017-0070

Baginski, M., Resat, H., and McCammon, J. A. (1997). Molecular properties of amphotericin B membrane channel: a molecular dynamics simulation. Mol. Pharmacol. 52 (4), 560-570. doi:10.1124/mol.52.4.560

Bahia, M. T., Diniz Lde, F., and Mosqueira, V. C. (2014). Therapeutical approaches under investigation for treatment of Chagas disease. Expert Opin. Investig. Drugs 23 (9), 1225-1237. doi:10.1517/13543784.2014.922952

Barr, S. C., Warner, K. L., Kornreic, B. G., Piscitelli, J., Wolfe, A., Benet, L., et al. (2005). A cysteine protease inhibitor protects dogs from cardiac damage during infection by Trypanosoma cruzi. Antimicrob. Agents Chemother. 49 (12), 5160-5161. doi:10.1128/AAC.49.12.5160-5161.2005

Basselin, M., Lawrence, F., and Robert-Gero, M. (1996). Pentamidine uptake in Leishmania donovani and Leishmania amazonensis promastigotes and axenic amastigotes. Biochem. J. W315 (2), 631-634. doi:10.1042/bj3150631

Beig, M., Oellien, F., Garoff, L., Noack, S., Krauth-Siegel, R. L., and Selzer, P. M. (2015). Trypanothione reductase: a target protein for a combined in vitro and in silico screening approach. PLoS Negl. Trop. Dis. 9 (6), e0003773. doi:10.1371/ journal.pntd.0003773

Berman, J. D. (1997). Human leishmaniasis: clinical, diagnostic, and chemotherapeutic developments in the last 10 years. Clin. Infect. Dis. 24 (4), 684-703. doi:10.1093/clind/24.4.684

Bern, C., Martin, D. L., and Gilman, R. H. (2011). Acute and congenital Chagas disease. Adv Parasitol. 75, 19-47. doi:10.1016/B978-0-12-385863-4.00002-2

Bhowmik, D., Jagadeesan, R., Rai, P., Nandi, R., Gugan, K., and Kumar, D. (2020). Evaluation of potential drugs against leishmaniasis targeting catalytic subunit of Leishmania donovani nuclear DNA primase using ligand based virtual screening, docking and molecular dynamics approaches. J. Biomol. Struct. Dyn. 1-15. doi:10.1080/07391102.2020.1739557

Biswaro, L. S., Garcia, M. P., da Silva, J. R., Neira Fuentes, L. F., Vera, A., Escobar, P., et al. (2019). Itraconazole encapsulated PLGA-nanoparticles covered with mannose as potential candidates against leishmaniasis. J. Biomed. Mater. Res. B 107 (3), 680-687. doi:10.1002/jbm.b.34161

Bond, C. S., Zhang, Y., Berriman, M., Cunningham, M. L., Fairlamb, A. H., and Hunter, W. N. (1999). Crystal structure of Trypanosoma cruzi trypanothione reductase in complex with trypanothione, and the structure-based discovery of new natural product inhibitors. Structure 7 (1), 81-89. doi:10.1016/s09692126(99)80011-2

Bora, N., and Jha, A. N. (2020). In silico metabolic pathway analysis identifying target against leishmaniasis-a kinetic modeling approach. Front. Genet. 11, 179. doi:10.3389/fgene.2020.00179

Borsari, C., Jiménez-Antón, M. D., Eick, J., Bifeld, E., Torrado, J. J., Olías-Molero, A. I., et al. (2019). Discovery of a benzothiophene-flavonol halting miltefosine and antimonial drug resistance in Leishmania parasites through the application of medicinal chemistry, screening and genomics. Eur. J. Med. Chem. 183, 111676. doi:10.1016/j.ejmech.2019.111676

Boswell, G. W., Buell, D., and Bekersky, I. (1998). AmBisome (liposomal amphotericin B): a comparative review. J. Clin. Pharmacol. 38 (7), 583-592. doi:10.1002/j.1552-4604.1998.tb04464.x

Brak, K., Kerr, I. D., Barrett, K. T., Fuchi, N., Debnath, M., Ang, K., et al. (2010). Nonpeptidic tetrafluorophenoxymethyl ketone cruzain inhibitors as promising new leads for Chagas disease chemotherapy. J. Med. Chem. 53 (4), 1763-1773. doi:10.1021/jm901633v

Britta, E. A., Scariot, D. B., Falzirolli, H., Da Silva, C. C., Ueda-Nakamura, T., Dias Filho, B. P., et al. (2015). 4-Nitrobenzaldehyde thiosemicarbazone: a new compound derived from S-(-)-limonene that induces mitochondrial alterations in epimastigotes and trypomastigotes of Trypanosoma cruzi. Parasitology 142 (7), 978-988. doi:10.1017/S0031182015000141

Brown, D. (2007). Unfinished business: target-based drug discovery. Drug Discov. Today 12 (23-24), 1007-1012. doi:10.1016/j.drudis.2007.10.017

Buckner, F. S., Bahia, M. T., Suryadevara, P. K., White, K. L., Shackleford, D. M., Chennamaneni, N. K., et al. (2012). Pharmacological characterization, structural studies, and in vivo activities of anti-Chagas disease lead compounds derived from tipifarnib. Antimicrob. Agents Chemother. 56 (9), 4914-4921. doi:10.1128/AAC.06244-11

Burguera, J., Burguera, M., De Pena, Y., Lugo, A., and Anez, N. (1993). Selective determination of antimony (III) and antimony (V) in serum and urine and of total antimony in skin biopsies of patients with cutaneous leishmaniasis treated with meglumine antimonate. Trace Elem. Med. 10 (2), 66-70.

Calogeropoulou, T., Angelou, P., Detsi, A., Fragiadaki, I., and Scoulica, E. (2008). Design and synthesis of potent antileishmanial cycloalkylidene-substituted ether phospholipid derivatives. J. Med. Chem. 51 (4), 897-908. doi:10.1021/ jm701166b

Capdeville, R., Buchdunger, E., Zimmermann, J., and Matter, A. (2002). Glivec (STI571, imatinib), a rationally developed, targeted anticancer drug. Nat. Rev. Drug Discov. 1 (7), 493-502. doi:10.1038/nrd839

Carlier, Y., Torrico, F., Sosa-Estani, S., Russomando, G., Luquetti, A., Freilij, H., et al. (2011). Congenital Chagas disease: recommendations for diagnosis, treatment and control of newborns, siblings and pregnant women. PLoS Negl. Trop. Dis. 5 (10), e1250. doi:10.1371/journal.pntd.0001250

Carter, N. S., Ben Mamoun, C., Liu, W., Silva, E. O., Landfear, S. M., Goldberg, D. E., et al. (2000). Isolation and functional characterization of the PfNT1 nucleoside transporter gene from Plasmodium falciparum. J. Biol. Chem. 275 (14), 10683-10691. doi:10.1074/jbc.275.14.10683

Chahed, M. K., Bellali, H., Ben Jemaa, S., and Bellaj, T. (2016). Psychological and psychosocial consequences of zoonotic cutaneous leishmaniasis among women in Tunisia: preliminary findings from an exploratory study. PLoS Negl. Trop. Dis. 10 (10), e0005090. doi:10.1371/journal.pntd.0005090

Chakraborty, A. K., and Majumder, H. K. (1988). Mode of action of pentavalent antimonials: specific inhibition of type I DNA topoisomerase of Leishmania donovani. Biochem. Biophys. Res. Commun. 152 (2), 605-611. doi:10.1016/ S0006-291X(88)80081-0

Chao, M. N., Storey, M., Li, C., Rodriguez, M. G., Di Salvo, F., Szajnman, S. H., et al. (2017). Selenium-containing analogues of WC-9 are extremely potent inhibitors of Trypanosoma cruzi proliferation. Bioorg. Med. Chem. 25 (24), 6435-6449. doi:10.1016/j.bmc.2017.10.016

Chatelain, E. (2017). Chagas disease research and development: is there light at the end of the tunnel? Comput. Struct. Biotechnol. J. 15, 98-103. doi:10.1016/j.csbj. 2016.12.002

Chavali, A. K., Blazier, A. S., Tlaxca, J. L., Jensen, P. A., Pearson, R. D., and Papin, J. A. (2012). Metabolic network analysis predicts efficacy of FDA-approved drugs targeting the causative agent of a neglected tropical disease. BMC Syst. Biol. 6 (1), 27. doi:10.1186/1752-0509-6-27 
Chen, M., Zhai, L., Christensen, S. B., Theander, T. G., and Kharazmi, A. (2001). Inhibition of fumarate reductase in Leishmania major and L. donovani by chalcones. Antimicrob. Agents Chemother. 45 (7), 2023-2029. doi:10.1128/ AAC.45.7.2023-2029.2001

Chow, L. Q., and Eckhardt, S. G. (2007). Sunitinib: from rational design to clinical efficacy. J. Clin. Oncol. 25 (7), 884-896. doi:10.1200/JCO.2006.06.3602

Coelho, A. C., Messier, N., Ouellette, M., and Cotrim, P. C. (2007). Role of the ABC transporter PRP1 (ABCC7) in pentamidine resistance in Leishmania amastigotes. Antimicrob. Agents Chemother. 51 (8), 3030-3032. doi:10.1128/ AAC.00404-07

Cohen, B. E. (2010). Amphotericin B membrane action: role for two types of ion channels in eliciting cell survival and lethal effects. J. Membr. Biol. 238 (1-3), 1-20. doi:10.1007/s00232-010-9313-y

Coimbra, E. S., Libong, D., Cojean, S., Saint-Pierre-Chazalet, M., Solgadi, A., Le Moyec, L., et al. (2010). Mechanism of interaction of sitamaquine with Leishmania donovani. J. Antimicrob. Chemother. 65 (12), 2548-2555. doi:10. 1093/jac/dkq371

Cole, A. (1944). Kala-azar in east Africa. Trans. R. Soc. Trop. Med. Hyg. 37 (6), 409-435. doi:10.1016/S0035-9203(44)90022-2

Corona, P., Gibellini, F., Cavalli, A., Saxena, P., Carta, A., Loriga, M., et al. (2012). Structure-based selectivity optimization of piperidine-pteridine derivatives as potent Leishmania pteridine reductase inhibitors. J. Med. Chem. 55 (19), 8318-8329. doi:10.1021/jm300563f

Cortes, L. A., Castro, L., Pesce, B., Maya, J. D., Ferreira, J., Castro-Castillo, V., et al. (2015). Novel gallate triphenylphosphonium derivatives with potent antichagasic activity. PLoS One 10 (8), e0136852. doi:10.1371/journal.pone. 0136852

Crunkhorn, S. (2016). Antiparasitic drugs: proteasome inhibition combats kinetoplastid infections. Nat. Rev. Drug Discov. 15 (10), 676-677. doi:10. 1038/nrd.2016.190

Cruz, I., Albertini, A., Barbeitas, M., Arana, B., Picado, A., Ruiz-Postigo, J. A., et al. (2019). Target product profile for a point-of-care diagnostic test for dermal leishmaniases. Parasite Epidemiol. Control 5, e00103. doi:10.1016/j.parepi.2019. e00103

da Matta Guedes, P. M., Urbina, J. A., de Lana, M., Afonso, L. C., Veloso, V. M., Tafuri, W. L., et al. (2004). Activity of the new triazole derivative albaconazole against Trypanosoma (Schizotrypanum) cruzi in dog hosts. Antimicrob. Agents Chemother. 48 (11), 4286-4292. doi:10.1128/AAC.48.11.4286-4292.2004

da Paixão, V. G., and da Rocha Pita, S. S. (2019). In silico identification and evaluation of new Trypanosoma cruzi trypanothione reductase (TcTR) inhibitors obtained from natural products database of the Bahia semi-arid region (NatProDB). Comput. Biol. Chem. 79, 36-47. doi:10.1016/j. compbiolchem.2019.01.009

da Rosa, R., de Moraes, M. H., Zimmermann, L. A., Schenkel, E. P., Steindel, M., and Bernardes, L. S. C. (2017). Design and synthesis of a new series of 3,5disubstituted isoxazoles active against Trypanosoma cruzi and Leishmania amazonensis. Eur. J. Med. Chem. 128, 25-35. doi:10.1016/j.ejmech.2017. 01.029

Das, B. B., Ganguly, A., and Majumder, H. K. (2008). DNA topoisomerases of Leishmania: the potential targets for anti-leishmanial therapy. Adv. Exp. Med. Biol. 625, 103-115. doi:10.1007/978-0-387-77570-8_9

Davidson, R. N., Croft, S. L., Scott, A., Maini, M., Moody, A. H., and Bryceson, A. D. (1991). Liposomal amphotericin B in drug-resistant visceral leishmaniasis. Lancet. 337 (8749), 1061-1062. doi:10.1016/0140-6736(91)91708-3

de Almeida Nogueira, N. P., de Souza, C. F., de Souza Saraiva, F. M., Sultano, P. E., Dalmau, S. R., Bruno, R. E., et al. (2011). Heme-induced ROS in Trypanosoma cruzi activates CaMKII-like that triggers epimastigote proliferation. One helpful effect of ROS. PLoS One 6 (10), e25935. doi:10.1371/journal.pone.0025935

de Azeredo, C. M., Avila, E. P., Pinheiro, D. L., Amarante, G. W., and Soares, M. J. (2017). Biological activity of the azlactone derivative EPA-35 against Trypanosoma cruzi. FEMS Microbiol. Lett. 364 (4), fnx020. doi:10.1093/ femsle/fnx020

de Menezes, J. P., Guedes, C. E., Petersen, A. L., Fraga, D. B., and Veras, P. S. (2015). Advances in development of new treatment for leishmaniasis. Biomed. Res. Int. 2015, 815023. doi:10.1155/2015/815023

Demicheli, C., Frezard, F., Lecouvey, M., and Garnier-Suillerot, A. (2002). Antimony $(\mathrm{V})$ complex formation with adenine nucleosides in aqueous solution. Biochim. Biophys. Acta 1570 (3), 192-198. doi:10.1016/s03044165(02)00198-8

Demoro, B., Caruso, F., Rossi, M., Benítez, D., González, M., Cerecetto, H., et al. (2012). Bisphosphonate metal complexes as selective inhibitors of Trypanosoma cruzi farnesyl diphosphate synthase. Dalton Trans. 41 (21), 6468-6476. doi:10.1039/C2DT12179D

Di Pisa, F., Landi, G., Dello Iacono, L., Pozzi, C., Borsari, C., Ferrari, S., et al. (2017). Chroman-4-One derivatives targeting pteridine reductase 1 and showing antiparasitic activity. Molecules 22 (3), 426. doi:10.3390/molecules22030426

Docampo, R., Vickers, T. J., and Beverley, S. M. (2011). Folate metabolic pathways in Leishmania. Essays Biochem. 51, 63-80. doi:10.1042/bse0510063

Dorlo, T. P., Balasegaram, M., Beijnen, J. H., and de Vries, P. J. (2012a). Miltefosine: a review of its pharmacology and therapeutic efficacy in the treatment of leishmaniasis. J. Antimicrob. Chemother. 67 (11), 2576-2597. doi:10.1093/jac/ dks275

Dorlo, T. P., Huitema, A. D., Beijnen, J. H., and de Vries, P. J. (2012b). Optimal dosing of miltefosine in children and adults with visceral leishmaniasis. Antimicrob. Agents Chemother. 56 (7), 3864-3872. doi:10.1128/AAC.00292-12

dos Santos Ferreira, C., Martins, P. S., Demicheli, C., Brochu, C., Ouellette, M., and Frézard, F. (2003). Thiol-induced reduction of antimony (V) into antimony (III): a comparative study with trypanothione, cysteinyl-glycine, cysteine and glutathione. Biometals 16 (3), 441-446. doi:10.1023/A:1022823605068

Doyle, P. S., Zhou, Y. M., Engel, J. C., and McKerrow, J. H. (2007). A cysteine protease inhibitor cures Chagas' disease in an immunodeficient-mouse model of infection. Antimicrob. Agents Chemother. 51 (11), 3932-3939. doi:10.1128/ AAC. $00436-07$

Dueñas-Romero, A. M., Loiseau, P. M., and Saint-Pierre-Chazalet, M. (2007). Interaction of sitamaquine with membrane lipids of Leishmania donovani promastigotes. Biochim. Biophys. Acta-Biomembr. 1768 (2), 246-252. doi:10. 1016/j.bbamem.2006.07.003

Durieu, E., Prina, E., Leclercq, O., Oumata, N., Gaboriaud-Kolar, N., Vougogiannopoulou, K., et al. (2016). From drug screening to target deconvolution: a target-based drug discovery pipeline using Leishmania casein kinase 1 isoform 2 to identify compounds with antileishmanial activity. Antimicrob. Agents Chemother. 60 (5), 2822-2833. doi:10.1128/ AAC.00021-16

Eldehna, W. M., Almahli, H., Ibrahim, T. M., Fares, M., Al-Warhi, T., Boeckler, F. M., et al. (2019). Synthesis, in vitro biological evaluation and in silico studies of certain arylnicotinic acids conjugated with aryl (thio) semicarbazides as a novel class of anti-leishmanial agents. Eur. J. Med. Chem. 179, 335-346. doi:10.1016/j. ejmech.2019.06.051

Eswaran, S., Adhikari, A. V., Chowdhury, I. H., Pal, N. K., and Thomas, K. D. (2010). New quinoline derivatives: synthesis and investigation of antibacterial and antituberculosis properties. Eur. J. Med. Chem. 45 (8), 3374-3383. doi:10. 1016/j.ejmech.2010.04.022

Fabbro, D. L., Danesi, E., Olivera, V., Codebo, M. O., Denner, S., Heredia, C., et al. (2014). Trypanocide treatment of women infected with Trypanosoma cruzi and its effect on preventing congenital Chagas. PLoS Negl. Trop. Dis. 8 (11), e3312. doi:10.1371/journal.pntd.0003312

Fairlamb, A. H., Blackburn, P., Ulrich, P., Chait, B. T., and Cerami, A. (1985). Trypanothione: a novel bis(glutathionyl)spermidine cofactor for glutathione reductase in trypanosomatids. Science 227 (4693), 1485-1487. doi:10.1126/ science. 3883489

Fernández, M. L., Marson, M. E., Ramirez, J. C., Mastrantonio, G., Schijman, A. G., Altcheh, J., et al. (2016). Pharmacokinetic and pharmacodynamic responses in adult patients with Chagas disease treated with a new formulation of benznidazole. Mem. Inst. Oswaldo Cruz. 111 (3), 218-221. doi:10.1590/ 0074-02760150401

Ferrer-Casal, M., Li, C., Galizzi, M., Stortz, C. A., Szajnman, S. H., Docampo, R., et al. (2014). New insights into molecular recognition of 1, 1-bisphosphonic acids by farnesyl diphosphate synthase. Bioorg. Med. Chem. 22 (1), 398-405. doi:10.1016/j.bmc.2013.11.010

Freitas, E. O., Nico, D., Alves-Silva, M. V., Morrot, A., Clinch, K., Evans, G. B., et al. (2015a). Immucillins ImmA and ImmH are effective and non-toxic in the treatment of experimental visceral leishmaniasis. PLoS Negl. Trop. Dis. 9 (12), e0004297. doi:10.1371/journal.pntd.0004297

Freitas, E. O., Nico, D., Guan, R., Meyer-Fernandes, J. R., Clinch, K., Evans, G. B., et al. (2015b). Immucillins impair Leishmania (L.) infantum chagasi and 
Leishmania (L.) amazonensis multiplication in vitro. PLoS One 10 (4), e0124183. doi:10.1371/journal.pone.0124183

Galvao, E. L., Rabello, A., and Cota, G. F. (2017). Efficacy of azole therapy for tegumentary leishmaniasis: a systematic review and meta-analysis. PLoS One 12 (10), e0186117. doi:10.1371/journal.pone.0186117

Ganguly, A., Banerjee, K., Chakraborty, P., Das, S., Sarkar, A., Hazra, A., et al. (2011). Overcoming multidrug resistance (MDR) in cancer in vitro and in vivo by a quinoline derivative. Biomed. Pharmacother. 65 (6), 387-394. doi:10.1016/ j.biopha.2011.04.024

Garcia-Calvo, M., Lisnock, J., Bull, H. G., Hawes, B. E., Burnett, D. A., Braun, M. P., et al. (2005). The target of ezetimibe is Niemann-Pick C1-Like 1 (NPC1L1). Proc. Natl. Acad. Sci. U.S.A. 102 (23), 8132-8137. doi:10.1073/pnas.0500269102

Ghaffarifar, F., Esavand Heydari, F., Dalimi, A., Hassan, Z. M., Delavari, M., and Mikaeiloo, H. (2015). Evaluation of apoptotic and antileishmanial activities of artemisinin on promastigotes and BALB/C mice infected with Leishmania major. Iran J. Parasitol. 10 (2), 258-267.

Ghedin, E., Zhang, W. W., Charest, H., Sundar, S., Kenney, R. T., and Matlashewski, G. (1997). Antibody response against a Leishmania donovani amastigote-stage-specific protein in patients with visceral leishmaniasis. Clin. Diagn. Lab. Immunol. 4 (5), 530-535.

Ghorbani, M., and Farhoudi, R. (2018). Leishmaniasis in humans: drug or vaccine therapy? Drug Des. Devel. Ther. 12, 25-40. doi:10.2147/DDDT.S146521

Gilbert, I. H. (2002). Inhibitors of dihydrofolate reductase in Leishmania and trypanosomes. Biochim. Biophys. Acta 1587 (2-3), 249-257. doi:10.1016/s09254439(02)00088-1

Gilbert, I. H. (2013). Drug discovery for neglected diseases: molecular target-based and phenotypic approaches: miniperspectives series on phenotypic screening for antiinfective targets. J. Med. Chem. 56 (20), 7719-7726. doi:10.1021/jm400362b

Godinho, J. L., Georgikopoulou, K., Calogeropoulou, T., de Souza, W., and Rodrigues, J. C. (2013). A novel alkyl phosphocholine-dinitroaniline hybrid molecule exhibits biological activity in vitro against Leishmania amazonensis. Exp. Parasitol. 135 (1), 153-165. doi:10.1016/j.exppara.2013.06.015

Goodwin, L. (1995). Pentostam ${ }^{\circledR}$ (sodium stibogluconate); a 50-year personal reminiscence. Trans. R. Soc. Trop. Med. Hyg. 89 (3), 339-341. doi:10.1016/ 0035-9203(95) $90572-3$

Hamill, R. J. (2013). Amphotericin B formulations: a comparative review of efficacy and toxicity. Drugs. 73 (9), 919-934. doi:10.1007/s40265-013-0069-4

Hartsel, S., and Bolard, J. (1996). Amphotericin B: new life for an old drug. Trends Pharmacol. Sci. 17 (12), 445-449. doi:10.1016/s0165-6147(96)01012-7

Herbrecht, R., Letscher, V., Andres, E., and Cavalier, A. (1999). Safety and efficacy of amphotericin B colloidal dispersion. An overview. Chemotherapy 45 (Suppl. 1), 67-76. doi:10.1159/000048472

Hoft, D. F., Farrar, P. L., Kratz-Owens, K., and Shaffer, D. (1996). Gastric invasion by Trypanosoma cruzi and induction of protective mucosal immune responses. Infect. Immun. 64 (9), 3800-3810. doi:10.1128/IAI.64.9.3800-3810.1996

Hotez, P. J., Molyneux, D. H., Fenwick, A., Kumaresan, J., Sachs, S. E., Sachs, J. D., et al. (2007). Control of neglected tropical diseases. N. Engl. J. Med. 357 (10), 1018-1027. doi:10.1056/NEJMra064142

Jaafari, M. R., Hatamipour, M., Alavizadeh, S. H., Abbasi, A., Saberi, Z., Rafati, S., et al. (2019). Development of a topical liposomal formulation of amphotericin B for the treatment of cutaneous leishmaniasis. Int. J. Parasitol. Drugs Drug Resist. 11, 156-165. doi:10.1016/j.ijpddr.2019.09.004

Jha, T. K., Sundar, S., Thakur, C. P., Bachmann, P., Karbwang, J., Fischer, C., et al. (1999). Miltefosine, an oral agent, for the treatment of Indian visceral leishmaniasis. N. Engl. J. Med. 341 (24), 1795-1800. doi:10.1056/NEJM199912093412403

Kandpal, M., and Tekwani, B. L. (1997). Polyamine transport systems of Leishmania donovani promastigotes. Life Sci. 60 (20), 1793-1801. doi:10. 1016/s0024-3205(97)00139-2

Keenan, M., Chaplin, J. H., Alexander, P. W., Abbott, M. J., Best, W. M., Khong, A., et al. (2013). Two analogues of fenarimol show curative activity in an experimental model of Chagas disease. J. Med. Chem. 56 (24), 10158-10170. doi: $10.1021 / \mathrm{jm} 401610 \mathrm{c}$

Khan, M. O. (2007). Trypanothione reductase: a viable chemotherapeutic target for antitrypanosomal and antileishmanial drug design. Drug Target Insights 2, 129-146. doi:10.1177/117739280700200007

Khare, S., Nagle, A. S., Biggart, A., Lai, Y. H., Liang, F., Davis, L. C., et al. (2016). Proteasome inhibition for treatment of leishmaniasis, Chagas disease and sleeping sickness. Nature. 537 (7619), 229-233. doi:10.1038/nature19339
Krieger, S., Schwarz, W., Ariyanayagam, M., Fairlamb, A., Krauth-Siegel, R., and Clayton, C. (2000). Trypanosomes lacking trypanothione reductase are avirulent and show increased sensitivity to oxidative stress. Mol. Microbiol. 35 (3), 542-552. doi:10.1046/j.1365-2958.2000.01721.x

Lai, A. F. E. J., Vrede, M. A., Soetosenojo, R. M., and Lai, A. F. R. F. (2002). Pentamidine, the drug of choice for the treatment of cutaneous leishmaniasis in Surinam. Int. J. Dermatol. 41 (11), 796-800. doi:10.1046/j.1365-4362.2002.01633.x

Lainson, R., and Rangel, E. F. (2005). Lutzomyia longipalpis and the ecoepidemiology of American visceral leishmaniasis, with particular reference to Brazil: a review. Mem. Inst. Oswaldo Cruz. 100 (8), 811-827. doi:10.1590/ s0074-02762005000800001

Langreth, S. G., Berman, J. D., Riordan, G. P., and Lee, L. S. (1983). Fine-structural alterations in Leishmania tropica within human macrophages exposed to antileishmanial drugs in vitro 1. J. Protozool 30 (3), 555-561. doi:10.1111/j. 1550-7408.1983.tb01421.x

Lechuga, G. C., Borges, J. C., Calvet, C. M., de Araújo, H. P., Zuma, A. A., do Nascimento, S. B., et al. (2016). Interactions between 4-aminoquinoline and heme: promising mechanism against Trypanosoma cruzi. Int. J. Parasitol. Drugs Drug Resist. 6 (3), 154-164. doi:10.1016/j.jipddr.2016.07.001

Liu, D., Zhang, T., Marshall, A. J., Okkenhaug, K., Vanhaesebroeck, B., and Uzonna, J. E. (2009). The p1108 isoform of phosphatidylinositol 3-kinase controls susceptibility to Leishmania major by regulating expansion and tissue homing of regulatory T cells. J. Immunol. 183 (3), 1921-1933. doi:10.4049/ jimmunol.0901099

Lucumi, A., Robledo, S., Gama, V., and Saravia, N. G. (1998). Sensitivity of Leishmania viannia panamensis to pentavalent antimony is correlated with the formation of cleavable DNA-protein complexes. Antimicrob. Agents Chemother. 42 (8), 1990-1995. doi:10.1128/AAC.42.8.1990

Maarouf, M., de Kouchkovsky, Y., Brown, S., Petit, P. X., and Robert-Gero, M. (1997). VivoInterference of paromomycin with mitochondrial activity of Leishmania. Exp. Cell Res. 232 (2), 339-348. doi:10.1006/excr.1997.3500

Maarouf, M., Lawrence, F., Croft, S. L., and Robert-Gero, M. (1995). Ribosomes of Leishmania are a target for the aminoglycosides. Parasitol. Res. 81 (5), 421-425. doi:10.1007/BF00931504

Manandhar, K. D., Yadav, T. P., Prajapati, V. K., Basukala, O., Aganja, R. P., Dude, A., et al. (2014). Nanonization increases the antileishmanial efficacy of amphotericin B: an ex vivo approach. Adv. Exp. Med. Biol. 808, 77-91. doi:10.1007/978-81-322-1774-9_7

Mandlik, V., Patil, S., Bopanna, R., Basu, S., and Singh, S. (2016). Biological activity of coumarin derivatives as anti-leishmanial agents. PLoS One 11 (10), e0164585. doi:10.1371/journal.pone.0164585

Mandlik, V., and Singh, S. (2016). Molecular docking and molecular dynamics simulation study of inositol phosphorylceramide synthase-inhibitor complex in leishmaniasis: insight into the structure based drug design. F1000Research 5, 1610. doi:10.12688/f1000research. 9151.2

Maroli, M., Feliciangeli, M. D., Bichaud, L., Charrel, R. N., and Gradoni, L. (2013). Phlebotomine sandflies and the spreading of leishmaniases and other diseases of public health concern. Med. Vet. Entomol. 27 (2), 123-147. doi:10.1111/j. 1365-2915.2012.01034.x

Martinez, S., and Marr, J. J. (1992). Allopurinol in the treatment of American cutaneous leishmaniasis. N. Engl. J. Med. 326 (11), 741-744. doi:10.1056/ NEJM199203123261105

Mateo, H., Marin, C., Perez-Cordon, G., and Sanchez-Moreno, M. (2008). Purification and biochemical characterization of four iron superoxide dismutases in Trypanosoma cruzi. Mem. Inst. Oswaldo Cruz 103 (3), 271-276. doi:10.1590/s0074-02762008000300008

Matlashewski, G. (2001). Leishmania infection and virulence. Med. Microbiol. Immunol. 190 (1-2), 37-42. doi:10.1007/s004300100076

Maya Arango, J., Orellana, M., Ferreira, J., Kemmerling Weis, U., López Muñoz, R., and Morello Casté, A. (2010). Chagas disease: present status of pathogenic mechanisms and chemotherapy. Biol. Res. 43, 323-331. doi:10.4067/S071697602010000300009

Meyerhoff, A. (1999). US food and drug administration approval of AmBisome (liposomal amphotericin B) for treatment of visceral leishmaniasis. Clin. Infect. Dis. 28 (1), 42-48. doi:10.1086/51508510.1086/515086

Modabber, F., Buffet, P. A., Torreele, E., Milon, G., and Croft, S. L. (2007). Consultative meeting to develop a strategy for treatment of cutaneous leishmaniasis. Kinetoplastid Biol. Dis. 6 (1), 3. doi:10.1186/1475-9292-6-3 
Moffat, J. G., Vincent, F., Lee, J. A., Eder, J., and Prunotto, M. (2017). Opportunities and challenges in phenotypic drug discovery: an industry perspective. Nat. Rev. Drug Discov. 16 (8), 531-543. doi:10.1038/nrd.2017.111

Moreno-Viguri, E., Jimenez-Montes, C., Martin-Escolano, R., Santivanez-Veliz, M., Martin-Montes, A., Azqueta, A., et al. (2016). In vitro and in vivo antiTrypanosoma cruzi activity of new arylamine mannich base-type derivatives. J. Med. Chem. 59 (24), 10929-10945. doi:10.1021/acs.jmedchem.6b00784

Morillo, C. A., Marin-Neto, J. A., Avezum, A., Sosa-Estani, S., Rassi, A., Jr, Rosas, F., et al. (2015). Randomized trial of benznidazole for chronic Chagas' cardiomyopathy. N. Engl. J. Med. 373 (14), 1295-1306. doi:10.1056/ NEJMoa1507574

Mukherjee, A., Padmanabhan, P. K., Sahani, M. H., Barrett, M. P., and Madhubala, R. (2006). Roles for mitochondria in pentamidine susceptibility and resistance in Leishmania donovani. Mol. Biochem. Parasitol. 145 (1), 1-10. doi:10.1016/j. molbiopara.2005.08.016

Muscia, G. C., Cazorla, S. I., Frank, F. M., Borosky, G. L., Buldain, G. Y., Asis, S. E., et al. (2011). Synthesis, trypanocidal activity and molecular modeling studies of 2-alkylaminomethylquinoline derivatives. Eur. J. Med. Chem. 46 (9), 3696-3703. doi:10.1016/j.ejmech.2011.05.035

Nagle, A., Biggart, A., Be, C., Srinivas, H., Hein, A., Caridha, D., et al. (2020). Discovery and characterization of clinical candidate LXE408 as a kinetoplastidselective proteasome inhibitor for the treatment of leishmaniases. J. Med. Chem. 63 (19), 10773-10781. doi:10.1021/acs.jmedchem.0c00499

Nagle, A. S., Khare, S., Kumar, A. B., Supek, F., Buchynskyy, A., Mathison, C. J., et al. (2014). Recent developments in drug discovery for leishmaniasis and human African trypanosomiasis. Chem. Rev. 114 (22), 11305-11347. doi:10.1021/cr500365f

Ndao, M., Beaulieu, C., Black, W. C., Isabel, E., Vasquez-Camargo, F., NathChowdhury, M., et al. (2014). Reversible cysteine protease inhibitors show promise for a Chagas disease cure. Antimicrob. Agents Chemother. 58 (2), 1167-1178. doi:10.1128/AAC.01855-13

Neumann, A., Czub, J., and Baginski, M. (2009). On the possibility of the amphotericin B-sterol complex formation in cholesterol and ergosterolcontaining lipid bilayers: a molecular dynamics study. J. Phys. Chem. B. 113 (48), 15875-15885. doi:10.1021/jp905133f

Nogueira, N. P., Saraiva, F. M. S., Oliveira, M. P., Mendonca, A. P. M., Inacio, J. D. F., Almeida-Amaral, E. E., et al. (2017). Heme modulates Trypanosoma cruzi bioenergetics inducing mitochondrial ROS production. Free Radic. Biol. Med. 108, 183-191. doi:10.1016/j.freeradbiomed.2017.03.027

Norcliffe, J. L., Mina, J. G., Alvarez, E., Cantizani, J., de Dios-Anton, F., Colmenarejo, G., et al. (2018). Identifying inhibitors of the Leishmania inositol phosphorylceramide synthase with antiprotozoal activity using a yeast-based assay and ultra-high throughput screening platform. Sci. Rep. 8 (1), 1-10. doi:10.1038/s41598-018-22063-9

Ortiz, D., Forquer, I., Boitz, J., Soysa, R., Elya, C., Fulwiler, A., et al. (2016). Targeting the cytochrome bcl complex of Leishmania parasites for discovery of novel drugs. Antimicrob. Agents Chemother. 60 (8), 4972-4982. doi:10.1128/AAC.00850-16

Pal, B., Murti, K., Siddiqui, N. A., Das, P., Lal, C. S., Babu, R., et al. (2017). Assessment of quality of life in patients with post kalaazar dermal leishmaniasis. Health Qual. Life Outcomes. 15 (1), 148. doi:10.1186/s12955-017-0720-y

Papanastasiou, I., Prousis, K. C., Georgikopoulou, K., Pavlidis, T., Scoulica, E., Kolocouris, N., et al. (2010). Design and synthesis of new adamantyl-substituted antileishmanial ether phospholipids. Bioorg. Med. Chem. Lett. 20 (18), 5484-5487. doi:10.1016/j.bmcl.2010.07.078

Paris, C., Loiseau, P. M., Bories, C., and Breard, J. (2004). Miltefosine induces apoptosis-like death in Leishmania donovani promastigotes. Antimicrob. Agents Chemother. 48 (3), 852-859. doi:10.1128/aac.48.3.852-859.2004

Pearson, R. D., and Sousa, A. Q. (1996). Clinical spectrum of leishmaniasis. Clin. Infect. Dis. 22 (1), 1-13. doi:10.1093/clinids/22.1.1

Piacenza, L., Peluffo, G., Alvarez, M. N., Martínez, A., and Radi, R. (2013). Trypanosoma cruzi antioxidant enzymes as virulence factors in Chagas disease. Antioxid. Redox Signal. 19 (7), 723-734. doi:10.1089/ars.2012.4618

Prates, F. V., Dourado, M. E., Silva, S. C., Schriefer, A., Guimaraes, L. H., Brito, M. D., et al. (2017). Fluconazole in the treatment of cutaneous leishmaniasis caused by leishmania braziliensis: a randomized controlled trial. Clin. Infect. Dis. 64 (1), 67-71. doi:10.1093/cid/ciw662

Punukollu, G., Gowda, R. M., Khan, I. A., Navarro, V. S., and Vasavada, B. C. (2007). Clinical aspects of the Chagas' heart disease. Int. J. Cardiol. 115 (3), 279-283. doi:10.1016/j.ijcard.2006.03.004
Purkait, B., Kumar, A., Nandi, N., Sardar, A. H., Das, S., Kumar, S., et al. (2012). Mechanism of amphotericin B resistance in clinical isolates of Leishmania donovani. Antimicrob. Agents Chemother. 56 (2), 1031-1041. doi:10.1128/AAC.00030-11

Rakotomanga, M., Blanc, S., Gaudin, K., Chaminade, P., and Loiseau, P. M. (2007). Miltefosine affects lipid metabolism in Leishmania donovani promastigotes. Antimicrob. Agents Chemother. 51 (4), 1425-1430. doi:10.1128/AAC.01123-06

Rassi, A., Jr, Rassi, A., and Marin-Neto, J. A. (2010). Chagas disease. Lancet 375 (9723), 1388-1402. doi:10.1016/S0140-6736(10)60061-X

Recher, M., Barboza, A. P., Li, Z.-H., Galizzi, M., Ferrer-Casal, M., Szajnman, S. H., et al. (2013). Design, synthesis and biological evaluation of sulfur-containing 1 , 1-bisphosphonic acids as antiparasitic agents. Eur. J. Med. Chem. 60, 431-440. doi:10.1016/j.ejmech.2012.12.015

Rodrígues-Poveda, C. A., González-Pacanowska, D., Szajnman, S. H., and Rodríguez, J. B. (2012). 2-alkylaminoethyl-1, 1-bisphosphonic acids are potent inhibitors of the enzymatic activity of Trypanosoma cruzi squalene synthase. Antimicrob. Agents Chemother. 56 (8), 4483-4486. doi:10.1128/AAC.00796-12

Sánchez, L. V., and Ramãrez, J. D. (2013). Congenital and oral transmission of American trypanosomiasis: an overview of physiopathogenic aspects. Parasitology 140 (2), 147. doi:10.1017/S0031182012001394

Scalise, M. L., Arrua, E. C., Rial, M. S., Esteva, M. I., Salomon, C. J., and Fichera, L. E. (2016). Promising efficacy of benznidazole nanoparticles in acute Trypanosoma cruzi murine model: in-vitro and in-vivo studies. Am. J. Trop. Med. Hyg. 95 (2), 388-393. doi:10.4269/ajtmh.15-0889

Schijman, A. G. (2006). Congenital chagas disease. Perspect. Med. Virol. 13, 223-258. doi:10.1016/S0168-7069(06)13012-8

Schmidt, A., and Krauth-Siegel, R. (2002). Enzymes of the trypanothione metabolism as targets for antitrypanosomal drug development. Curr. Top. Med. Chem. 2 (11), 1239-1259. doi:10.2174/1568026023393048

Sen, R., Ganguly, S., Saha, P., and Chatterjee, M. (2010). Efficacy of artemisinin in experimental visceral leishmaniasis. Int. J. Antimicrob. Agents. 36 (1), 43-49. doi:10.1016/j.ijantimicag.2010.03.008

Shaked-Mishan, P., Ulrich, N., Ephros, M., and Zilberstein, D. (2001). Novel intracellular $\mathrm{SbV}$ reducing activity correlates with antimony susceptibility in Leishmania donovani. J. Biol. Chem. 276 (6), 3971-3976. doi:10.1074/jbc.M005423200

Shakibaie, M., Forootanfar, H., Golkari, Y., Mohammadi-Khorsand, T., and Shakibaie, M. R. (2015). Anti-biofilm activity of biogenic selenium nanoparticles and selenium dioxide against clinical isolates of Staphylococcus aureus, Pseudomonas aeruginosa, and Proteus mirabilis. J. Trace Elem. Med. Biol. 29, 235-241. doi:10.1016/j.jtemb.2014.07.020

Shang, N., Li, Q., Ko, T.-P., Chan, H.-C., Li, J., Zheng, Y., et al. (2014). Squalene synthase as a target for Chagas disease therapeutics. PLoS Pathog. 10 (5), e1004114. doi:10.1371/journal.ppat.1004114

Shikanai-Yasuda, M. A., and Carvalho, N. B. (2012). Oral transmission of Chagas disease. Clin. Infect. Dis. 54 (6), 845-852. doi:10.1093/cid/cir956

Simitsopoulou, M., Roilides, E., Dotis, J., Dalakiouridou, M., Dudkova, F., Andreadou, E., et al. (2005). Differential expression of cytokines and chemokines in human monocytes induced by lipid formulations of amphotericin B. Antimicrob. Agents Chemother. 49 (4), 1397-1403. doi:10.1128/AAC.49.4.1397-1403.2005

Soto-Mancipe, J., Grogl, M., and Berman, J. D. (1993). Evaluation of pentamidine for the treatment of cutaneous leishmaniasis in Colombia. Clin. Infect. Dis. 16 (3), 417-425. doi:10.1093/clind/16.3.417

Soy, D., Aldasoro, E., Guerrero, L., Posada, E., Serret, N., Mejia, T., et al. (2015). Population pharmacokinetics of benznidazole in adult patients with Chagas disease. Antimicrob. Agents Chemother. 59 (6), 3342-3349. doi:10.1128/AAC.05018-14

Stickles, A. M., De Almeida, M. J., Morrisey, J. M., Sheridan, K. A., Forquer, I. P., Nilsen, A., et al. (2015). Subtle changes in endochin-like quinolone structure alter the site of inhibition within the cytochrome bcl complex of Plasmodium falciparum. Antimicrob. Agents Chemother. 59 (4), 1977-1982. doi:10.1128/AAC.04149-14

Sundar, S., and Olliaro, P. L. (2007). Miltefosine in the treatment of leishmaniasis: clinical evidence for informed clinical risk management. Ther. Clin. Risk Manag. 3 (5), 733-740.

Swinney, D. C., and Anthony, J. (2011). How were new medicines discovered? Nat. Rev. Drug Discov. 10 (7), 507-519. doi:10.1038/nrd3480

Swinney, D. C. (2013). Phenotypic vs. target-based drug discovery for first-in-class medicines. Clin. Pharmacol. Ther. 93 (4), 299-301. doi:10.1038/clpt.2012.236

Tarleton, R. L., Gürtler, R. E., Urbina, J. A., Ramsey, J., and Viotti, R. (2014). Chagas disease and the London declaration on neglected tropical diseases. PLoS Negl. Trop. Dis. 8 (10), e3219. doi:10.1371/journal.pntd.0003219 
Tasbihi, M., Shekari, F., Hajjaran, H., Masoori, L., and Hadighi, R. (2019). Mitochondrial proteome profiling of Leishmania tropica. Microb. Pathog. 133, 103542. doi:10.1016/j.micpath.2019.103542

Temperton, N. J., Wilkinson, S. R., Meyer, D. J., and Kelly, J. M. (1998). Overexpression of superoxide dismutase in Trypanosoma cruzi results in increased sensitivity to the trypanocidal agents gentian violet and benznidazole. Mol. Biochem. Parasitol. 96 (1-2), 167-176. doi:10.1016/ s0166-6851(98)00127-3

Tiwari, B., Pahuja, R., Kumar, P., Rath, S. K., Gupta, K. C., and Goyal, N. (2017). Nanotized curcumin and miltefosine, a potential combination for treatment of experimental visceral leishmaniasis. Antimicrob. Agents Chemother. 61 (3). doi:10.1128/AAC.01169-16

Toledo, A. C. D. C., Jr, da Silva, R. E., Carmo, R. F., Amaral, T. A., Luz, Z. M. P., and Rabello, A. (2013). Assessment of the quality of life of patients with cutaneous leishmaniasis in Belo Horizonte, Brazil, 2009-2010. A pilot study. Trans. R. Soc. Trop. Med. Hyg. 107 (5), 335-336. doi:10.1093/trstmh/trt021

Urbina, J. A., Concepcion, J. L., Rangel, S., Visbal, G., and Lira, R. (2002). Squalene synthase as a chemotherapeutic target in Trypanosoma cruzi and Leishmania mexicana. Mol. Biochem. Parasitol. 125 (1-2), 35-45. doi:10.1016/S01666851(02)00206-2

Valle, I. V., Machado, M. E., Araujo, C., da Cunha-Junior, E. F., da Silva Pacheco, J., Torres-Santos, E. C., et al. (2019). Oral pentamidine-loaded poly(d,l-lactic-coglycolic) acid nanoparticles: an alternative approach for leishmaniasis treatment. Nanotechnology 30 (45), 455102. doi:10.1088/1361-6528/ab373e

Vasudevan, G., Carter, N. S., Drew, M. E., Beverley, S. M., Sanchez, M. A., Seyfang, A., et al. (1998). Cloning of Leishmania nucleoside transporter genes by rescue of a transport-deficient mutant. Proc. Natl. Acad. Sci. U.S.A. 95 (17), 9873-9878. doi:10.1073/pnas.95.17.9873

Vázquez, K., Paulino, M., O Salas, C., J Zarate-Ramos, J., Vera, B., and Rivera, G. (2017). Trypanothione reductase: a target for the development of antiTrypanosoma cruzi drugs. Mini Rev. Med. Chem. 17 (11), 939-946. doi:10. 2174/1389557517666170315145410

Vera, A. M., Casadiego, O. A., Mantilla, J. C., and Escobar, P. (2018). Evaluation of ketoconazole formulations for topical use in cutaneous leishmaniasis caused by Leishmania (Viannia). Rev. Peru Med. Exp. Salud Publica. 35 (3), 476. doi:10. 17843/rpmesp.2018.353.3531

Verma, N. K., and Dey, C. S. (2004). Possible mechanism of miltefosine-mediated death of Leishmania donovani. Antimicrob. Agents Chemother. 48 (8), 3010-3015. doi:10.1128/AAC.48.8.3010-3015.2004

Vieira, P. S., Souza, T., Honorato, R. V., Zanphorlin, L. M., Severiano, K. U., Rocco, S. A., et al. (2017). Pyrrole-indolinone SU11652 targets the nucleoside diphosphate kinase from Leishmania parasites. Biochem. Biophys. Res. Commun. 488 (3), 461-465. doi:10.1016/j.bbrc.2017.05.048

Villa-Pulgarín, J. A., Gajate, C., Botet, J., Jimenez, A., Justies, N., Varela, -M, R. E., et al. (2017). Mitochondria and lipid raft-located FOF1-ATP synthase as major therapeutic targets in the antileishmanial and anticancer activities of ether lipid edelfosine. PLoS Negl. Trop. Dis. 11 (8), e0005805. doi:10.1371/journal.pntd.0005805

Vinuesa, T., Herraez, R., Oliver, L., Elizondo, E., Acarregui, A., Esquisabel, A., et al. (2017). Benznidazole nanoformulates: a chance to improve therapeutics for chagas disease. Am. J. Trop. Med. Hyg. 97 (5), 1469-1476. doi:10.4269/ajtmh. 17-0044

Wadhone, P., Maiti, M., Agarwal, R., Kamat, V., Martin, S., and Saha, B. (2009). Miltefosine promotes IFN- $\gamma$-dominated anti-leishmanial immune response. J. Immunol. 182 (11), 7146-7154. doi:10.4049/jimmunol.0803859

Walker, J., and Saravia, N. G. (2004). Inhibition of Leishmania donovani promastigote DNA topoisomerase I and human monocyte DNA topoisomerases I and II by antimonial drugs and classical antitopoisomerase agents. J. Parasitol. 90 (5), 1155-1162. doi:10.1645/GE-3347

Walsh, T. J., Goodman, J. L., Pappas, P., Bekersky, I., Buell, D. N., Roden, M., et al. (2001). Safety, tolerance, and pharmacokinetics of high-dose liposomal amphotericin B (AmBisome) in patients infected with Aspergillus species and other filamentous fungi: maximum tolerated dose study. Antimicrob.
Agents Chemother. 45 (12), 3487-3496. doi:10.1128/AAC.45.12.3487-3496. 2001

Want, M. Y., Islammudin, M., Chouhan, G., Ozbak, H. A., Hemeg, H. A., Chattopadhyay, A. P., et al. (2017). Nanoliposomal artemisinin for the treatment of murine visceral leishmaniasis. Int. J. Nanomedicine 12, 2189-2204. doi:10.2147/IJN.S106548

Want, M. Y., Islamuddin, M., Chouhan, G., Dasgupta, A. K., Chattopadhyay, A. P., and Afrin, F. (2014). A new approach for the delivery of artemisinin: formulation, characterization, and ex-vivo antileishmanial studies. J. Colloid Interf. Sci. 432, 258-269. doi:10.1016/j.jcis.2014.06.035

Want, M. Y., Islamuddin, M., Chouhan, G., Ozbak, H. A., Hemeg, H. A., Dasgupta, A. K., et al. (2015). Therapeutic efficacy of artemisinin-loaded nanoparticles in experimental visceral leishmaniasis. Colloids Surf. B Biointerfaces 130, 215-221. doi:10.1016/j.colsurfb.2015.04.013

WHO (2020). Neglected tropical diseases: treating more than one billion people for the fifth consecutive year. Geneva, Switzerland: World Health Organization. Available at: https://www.who.int/neglected_diseases/news/treating-morethan-one-billion-people-fifth-consecutive-year/en/\#: :text=25\%20September \%202020\%20\%7C\%20Geneva\%20\%E2\%80\%93\%E2\%80\%93,large\%2Dscale\% 20 preventive $\% 20$ treatment $\% 20$ campaigns.

WHO-Expert-Committee (2002). "Control of chagas disease," in World Health Organization Technical Report Series. Vol. 905, 1-109. Available at: https:// pubmed.ncbi.nlm.nih.gov/12092045/.

Wijnant, G.-J., Van Bocxlaer, K., Yardley, V., Harris, A., Alavijeh, M., SilvaPedrosa, R., et al. (2018). Comparative efficacy, toxicity and biodistribution of the liposomal amphotericin B formulations Fungisome ${ }^{\circledR}$ and AmBisome ${ }^{\circledR}$ in murine cutaneous leishmaniasis. Int. J. Parasitol. Drugs Drug Resist. 8 (2), 223-228. doi:10.1016/j.ijpddr.2018.04.001

Wyllie, S., Brand, S., Thomas, M., De Rycker, M., Chung, C.-w., Pena, I., et al. (2019). Preclinical candidate for the treatment of visceral leishmaniasis that acts through proteasome inhibition. Proc. Natl. Acad. Sci. U.S.A. 116 (19), 9318-9323. doi:10.1073/pnas.1820175116

Yanik, M., Gurel, M. S., Simsek, Z., and Kati, M. (2004). The psychological impact of cutaneous leishmaniasis. Clin. Exp. Dermatol. 29 (5), 464-467. doi:10.1111/j. 1365-2230.2004.01605.x

Yasur-Landau, D., Jaffe, C. L., David, L., and Baneth, G. (2016). Allopurinol resistance in Leishmania infantum from dogs with disease relapse. PLoS Negl. Trop. Dis. 10 (1), e0004341. doi:10.1371/journal.pntd.0004341

Yeates, C. (2002). Sitamaquine (GlaxoSmithKline/Walter Reed army Institute). Curr. Opin. Investig. Drugs 3 (10), 1446-1452.

Zhai, L., Blom, J., Chen, M., Christensen, S. B., and Kharazmi, A. (1995). The antileishmanial agent licochalcone $\mathrm{A}$ interferes with the function of parasite mitochondria. Antimicrob. Agents Chemother. 39 (12), 2742-2748. doi:10.1128/ aac.39.12.2742

Zhai, L., Chen, M., Blom, J., Theander, T. G., Christensen, S. B., and Kharazmi, A. (1999). The antileishmanial activity of novel oxygenated chalcones and their mechanism of action. J. Antimicrob. Chemother. 43 (6), 793-803. doi:10.1093/jac/43.6.793

Zhou, Y., Messier, N., Ouellette, M., Rosen, B. P., and Mukhopadhyay, R. (2004). Leishmania major LmACR2 is a pentavalent antimony reductase that confers sensitivity to the drug pentostam. J. Biol. Chem. 279 (36), 37445-37451. doi:10. 1074/jbc.M404383200

Conflict of Interest: The authors declare that the research was conducted in the absence of any commercial or financial relationships that could be construed as a potential conflict of interest.

Copyright (C) $2021 \mathrm{~J}, \mathrm{M}$ and Chanda. This is an open-access article distributed under the terms of the Creative Commons Attribution License (CC BY). The use, distribution or reproduction in other forums is permitted, provided the original author(s) and the copyright owner(s) are credited and that the original publication in this journal is cited, in accordance with accepted academic practice. No use, distribution or reproduction is permitted which does not comply with these terms. 